Florida International University

FIU Digital Commons

$3-24-2020$

\title{
Targeted Presentation Skill Trainings to Nurture Construction Management Students at Florida International University
}

\author{
Gabriella D. Santi Kasabdji \\ Florida International University, gsant122@fiu.edu
}

Follow this and additional works at: https://digitalcommons.fiu.edu/etd

Part of the Construction Engineering and Management Commons, and the Engineering Education Commons

\section{Recommended Citation}

Santi Kasabdji, Gabriella D., "Targeted Presentation Skill Trainings to Nurture Construction Management Students at Florida International University" (2020). FIU Electronic Theses and Dissertations. 4420. https://digitalcommons.fiu.edu/etd/4420

This work is brought to you for free and open access by the University Graduate School at FIU Digital Commons. It has been accepted for inclusion in FIU Electronic Theses and Dissertations by an authorized administrator of FIU Digital Commons. For more information, please contact dcc@fiu.edu. 


\title{
FLORIDA INTERNATIONAL UNIVERSITY
}

Miami, Florida

TARGETED PRESENTATION SKILL TRAININGS TO NURTURE CONSTRUCTION MANAGEMENT STUDENTS AT FLORIDA INTERNATIONAL UNIVERSITY

\author{
A thesis submitted in partial fulfillment of \\ the requirements for the degree of \\ MASTER OF SCIENCE \\ in \\ CONSTRUCTION MANAGEMENT \\ by
}

Gabriella D. Santi Kasabdji 
To: Dean John L. Volakis

College of Engineering and Computing

This thesis, written by Gabriella D. Santi Kasabdji, and entitled Targeted Presentation Skill Trainings to Nurture Construction Management Students at Florida International University, having been approved in respect to style and intellectual content, is referred to you for judgment.

We have read this thesis and recommend that it be approved.

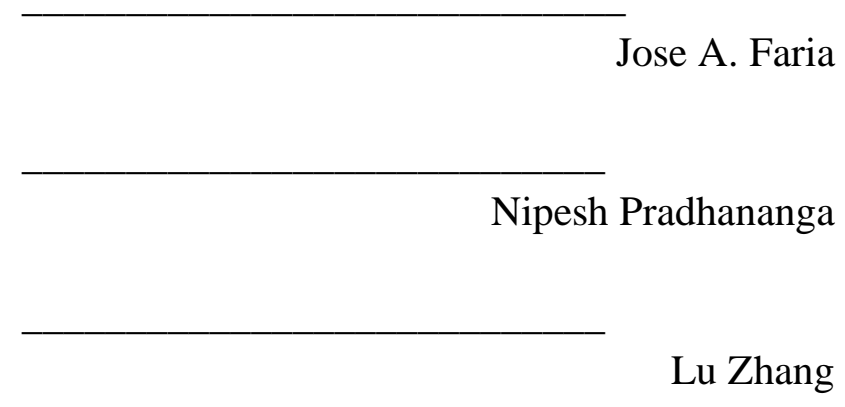

Mohamed ElZomor, Major Professor

Date of Defense: March 24, 2020

The thesis of Gabriella D. Santi Kasabdji is approved.

Dean John L. Volakis College of Engineering and Computing

Andrés G. Gil Vice President for Research and Economic Development and Dean of the University Graduate School

Florida International University, 2020 


\section{DEDICATION}

I would like to dedicate my work to my parents for being the best role models, and for always giving me their constant love and support throughout my life. 


\section{ACKNOWLEDGMENTS}

The author would like to thank Dr. ElZomor, Dr. Zhang, Dr. Pradhananga, Dr. Faria and Dr. Kalasapudi, for their support and contribution throughout the research. 


\begin{abstract}
OF THE THESIS
TARGETED PRESENTATION SKILL TRAININGS TO NURTURE CONSTRUCTION MANAGEMENT STUDENTS AT FLORIDA INTERNATIONAL UNIVERSITY

by
\end{abstract}

Gabriella D. Santi Kasabdji

Florida International University, 2020

Miami, Florida

Professor Mohamed ElZomor, Major Professor

In today's fast-paced work environment, competent construction managers (CM) are vital for project success. However, to be competent, these professionals require the mastery of not only technical skills but also soft skills that enable them to achieve their full potential. Regardless, many CM prize technical abilities over the day-to-day writing, speaking, and overall soft skills, assuming these are not as important to the knowledge of complex concepts. Industry leaders confirm this, as evidence states graduate construction managers lack the basic communication skills to hit the ground running. That said, academic programs should seek to adapt and nurture these vital skill sets. For this reason, this research seeks to understand FIU-STEM students' current communication skills and advance CM students' presentation skills through three multi-context communicationtrainings. These activities offered students opportunities to enhance their presentation performance, improve their confidence, and overcome common presentation issues, thus increasing their chances to thrive in their careers. 


\section{TABLE OF CONTENTS}

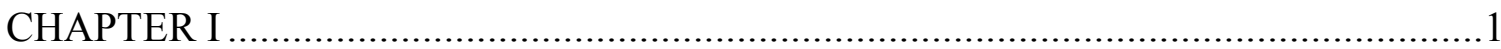

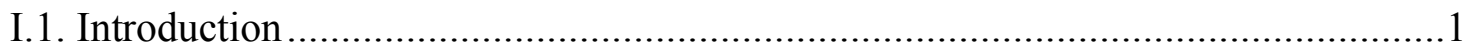

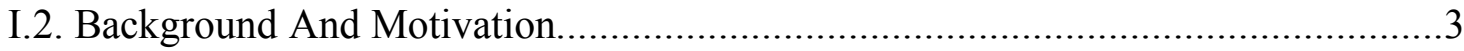

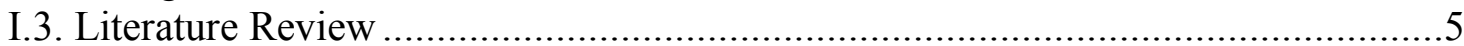

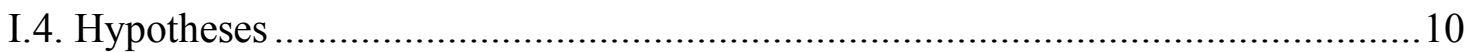

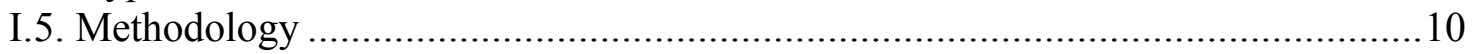

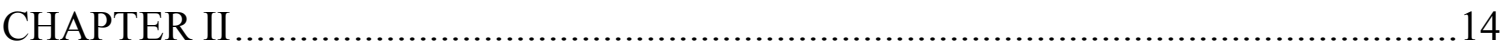

II.1. Creating a Benchmark for FIU STEM Students' Communication Skills .............14

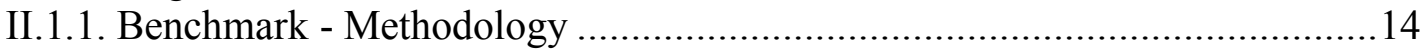

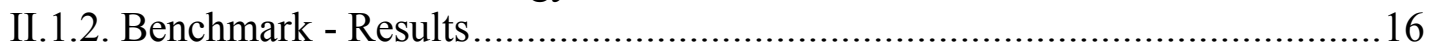

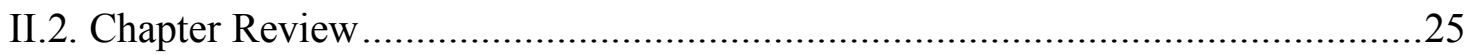

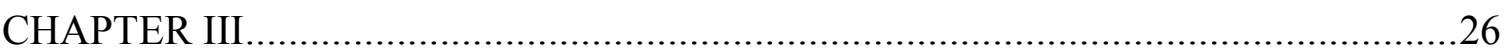

Iii.1. Implementation Of Three Communication Training To Nurture Cm Students'

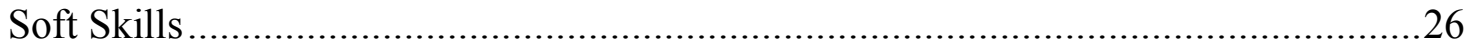

Iii.1.1. Activity 1 - Lecture Style Presentation Skills Training ..............................27

Iii.1.2. Activity 2 - Vr Presentation Simulation Training ......................................28

Iii.1.3. Activity 3 - Social Media Communication Skills Activity .............................31

Iii.2. Implementation Of Activities - Methodology....................................................34

Iii.3. Results For Group A...................................................................................38

Iii.3.1. Results For The Peer-Evaluations Of Activity 1 For Group A ......................38

Iii.3.2. Results Of The Peer-Evaluation For Activity 2 For Group A........................40

Iii.4. Results For The Peer-Evaluations For Group B ............................................43

Iii.5. Results Of The Peer-Evaluations Of Group C ................................................46

Iii.7. Implementation Of Activities - Conclusion.....................................................

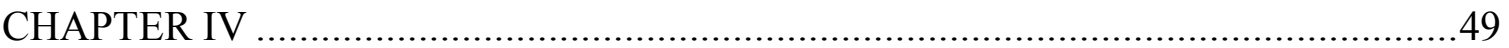

Iv.1. Student Perception On Communication Skill Trainings - Exit Survey ...............49

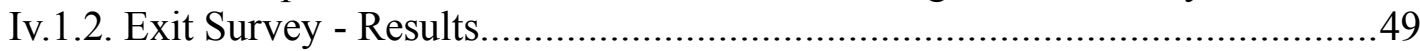

Iv.1.3. Exit Survey - Conclusion ........................................................................57

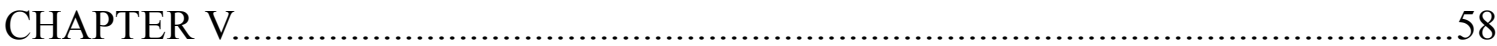

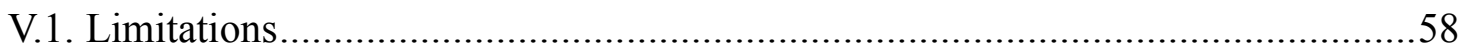

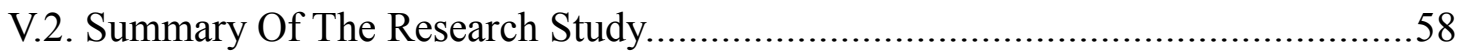

V.3. Authors' Interpretation Of The Research ..........................................................6

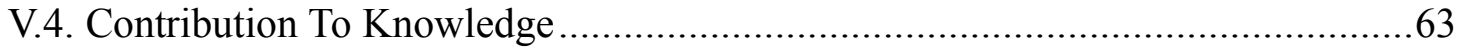

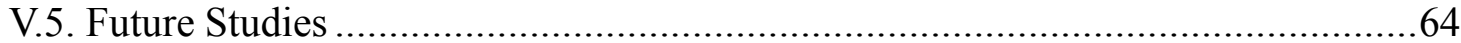

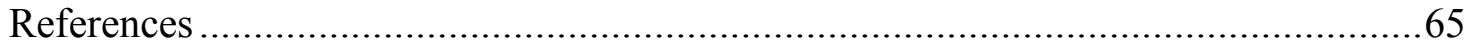

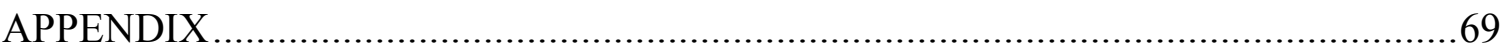




\section{LIST OF TABLES}

TABLE PAGE

Table 1. Coefficients and P-Value from Ordered Probit Analysis................................24

Table 2. Paired T Test Results for BCN5585/BCN4570 - Activity 1 ...........................39

Table 3. Paired T Test Results for Group A - Activity 2.........................................41

Table 4. Paired T Test Results for BCN1013 .......................................................44

Table 5. Paired T Test Results for BCN2253 .....................................................44

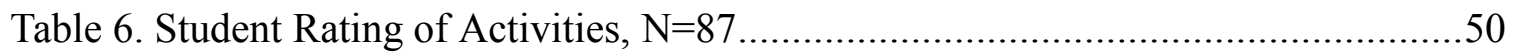

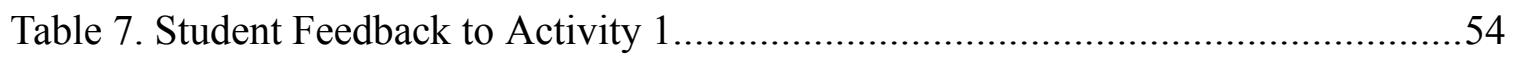

Table 8. Student Feedback to Activity 2 .................................................................55

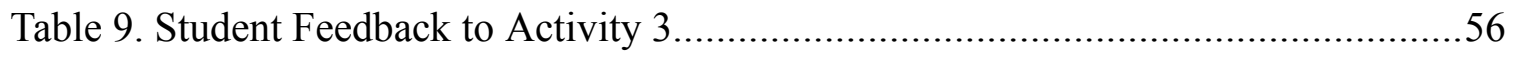




\section{LIST OF FIGURES}

FIGURE

PAGE

Figure 1. Research Overview ..................................................................... 13

Figure 2. Respondents' Socio-Demographic Profile - Benchmark Survey, N=327 .........17

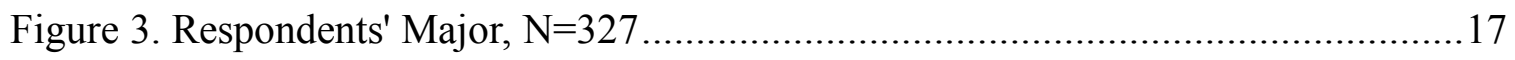

Figure 4. Students' Perspective on Developing Communication Skills, N=327.............18

Figure 5. Respondents' Perspective on the Importance of Presentation Skills, $N=327 \ldots . .19$

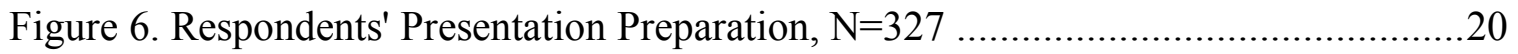

Figure 7. STEM Students' Presentation Skill Self-Assessment, $\mathrm{N}=327 \ldots \ldots \ldots \ldots \ldots \ldots \ldots . . . . .21$

Figure 8. STEM Student Perception on Presentation Skill Importance, $\mathrm{N}=327 \ldots \ldots \ldots \ldots . . .22$

Figure 9. Lecture-Style Communication Skills Training .........................................28

Figure 10. Students in the VR Presentation Simulation Sessions ................................29

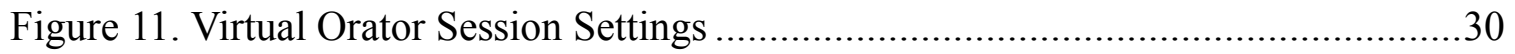

Figure 12. LinkedIn - Soft Skills for Construction Managers Group............................31

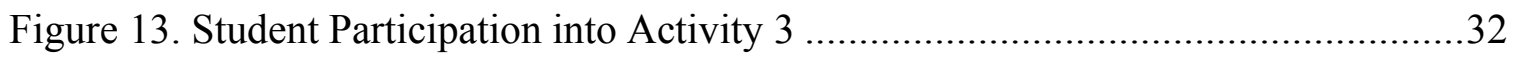

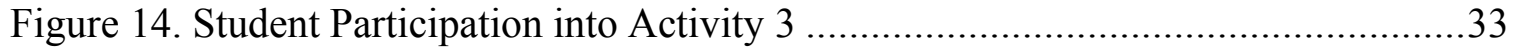

Figure 15. Presentation Evaluation Criteria ............................................................36

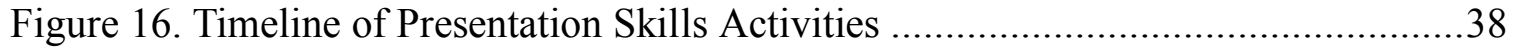

Figure 17. Group A Students' Professional Skills Development, $N=34$......................40

Figure 18.Group A Students' Professional Skill Development - Activity 2, N=34 ........42

Figure 19. Virtual Orator Presentation Simulation Report ....................................43

Figure 20. BCN1013 Student Skills Improvement Throughout the Activities................45

Figure 21. BCN2253 Student Skills Improvement Throughout the Activities................46

Figure 22. Group C Student Skills Improvement Throughout the Activities .................46 


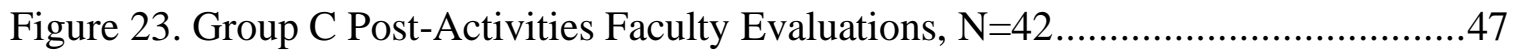

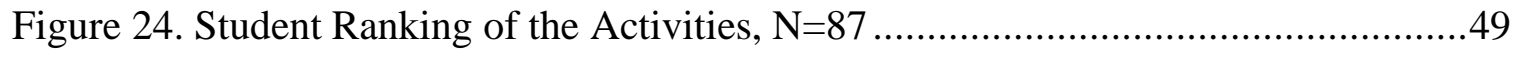

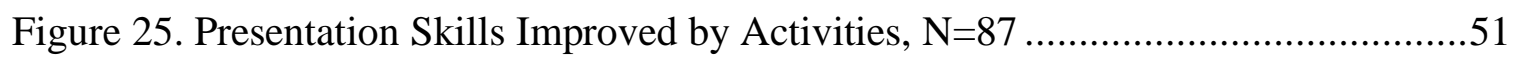

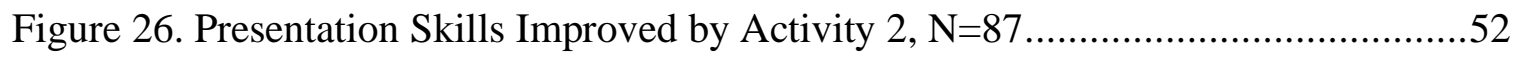

Figure 27. Student Improvement Through Activity 3, N=87 ................................52

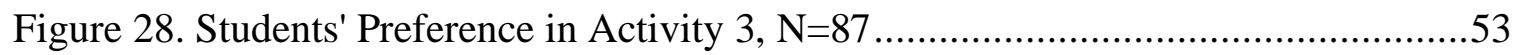




\section{CHAPTER I}

\section{I.1. Introduction}

Education in the 20th century is not perceived as an objective for a restricted few, yet it is the pillar of success that forms the primary backbone of our economy. Due to the rapid growth in economic structures and the globalized competitiveness of the market, the job industry is expected to raise the bar on our future workforce [1]. Therefore, students will require an academic career that develops and nurtures their professional skills far beyond the technical skills, and thus ensures thriving in such competitive work environments [2]. This is especially true for STEM students, specifically construction management (CM) students, who must master multiple professional skills to succeed in these ever-changing competitive work environments. However, studies have expressed that recent graduates lack certain soft skills, particularly communication and presentation skills, at the time of entering the workforce [3]. To date, conventional engineering education depends on ineffective paradigms, tiring introductory courses, and timeworn learning techniques [4]. Although academic programs have taken a certain level of initiative to address this issue, many educational institutions rely on traditional approaches and extracurricular activities, which have shown to be obsolete. High education institutions must incorporate alternative learning pedagogies that go beyond traditional approaches, thus ensuring the development of their students' skills [5].

To understand FIU students' specific lack of communication skills, a benchmark survey was administered to 327 STEM students at the College of Engineering and Computing. This survey allowed the author to understand the students' current strengths and 
deficiencies in their presentation skills. Additionally, to understand and identify the impact of students' socio-demographic profiles on their presentation skills, an ordinal probit regression model was conducted. Next, this research analyzed the implementation of three alternative and innovative learning techniques. The activities consisted of a Lecture-Style Communication Skills Training, a Virtual Reality (VR) Presentation Simulation, and a Social Media Communication Skills Activity. The activities' implementation was monitored to assess their effectiveness in aiding students' professional presentation skills development. Peer evaluations were obtained throughout five construction management courses, to measure the effectiveness. Finally, an exit survey was administered to the students involved in this research to obtain their feedback into the different innovative trainings. In the end, the results of this research emphasize the importance of focusing on developing our CM students' presentation skills. Results also provide valuable insights into the implementation of alternative learning pedagogies as in-class or informal training that integrate students' development skills in addition to technical contents. 


\section{I.2. Background and Motivation}

From providing access to clean water to managing large-scale infrastructure projects, the grand challenges that engineers face in the modern world are equally technical and social. To overcome these challenges, aspiring engineers must not only become experts on the technical aspects of their specific field but also develop the soft skills that enable them to fully leverage their technical knowledge in an evolving, increasingly complex and globalized work environment [6]. In today's world, where multicultural teams are encouraged and considered the norm rather than an exception, technical professionals must be able to communicate effectively in order to realize their full potential [7]. However, these skills have become stifled, as the typical STEM graduate spends approximately five years building her/his technical expertise, with little to no time devoted to human communication training [8].

Evidence suggests that in the industry, STEM graduates lack the basic required communication skill to "hit the ground running" [3]. Numerous industry assessments confirm this fact, not to mention that students themselves attest that formal communication skills are one of their primary shortcomings [9],[10]. For instance, reports by the Society of Manufacturing Engineers stated that a significant percentage of their professionals could not communicate their ideas well in writing [11]. Another recent study indicated that a high percentage of professionals in construction reported that ineffective communication skills are one reason that causes problems in their place of work [12]. Overall, oral and written communication skills are actually one of the primary strengths required of new graduates that ultimately affect their success in the workplace [13][14]. Overall, the 
literature suggests that the main communication skills students should seek to achieve to successfully deliver presentations and communicate effectively are delivery, body language, language skills, organization \& content, use of visual aids, and ability to engage audiences [15],[16].

While graduates state they had gained analytical and problem-solving skills, as well as decision-making abilities throughout their academic preparation, many indicate their communication and presentation skills did not improve through their education [7]. Moreover, $38 \%$ of new engineering graduates across all engineering fields state that while communication skills are one of the most important factors affecting their advancement and success within the industry, this area is often the most undeveloped during their academic preparation [17]. Likewise, while communication skills are crucial to $\mathrm{CM}$ practices, research studies report that these skills are being incompetently developed in CM educational programs and curricula nationwide [18][19][20]. Overall, literature states a high deficiency across STEM students' soft skills development in higher education.

This lack of skills can have serious cost implications for industries, as there is an increasing pressure to cut costs and improve efficiency. For instance, careers such as construction management require interaction with people from different careers, education levels, and backgrounds. Their work is complex and technical, yet they need to be able to efficiently communicate with individuals who might not have the same technical expertise. For these types of careers, where extensive collaboration is required, professionals must work to ensure they possess adequate communication and presentation skills since studies have 
proven that poor presentation skills could hinder a persons' career [21]. Thus, if CM professionals lack these basic soft skills, they will not be able to communicate well, engage in active listening, and most likely will have difficulty contributing to important group discussions. These individuals, instead of making progress, will only waste valuable time, resources, and energy. In the long run, a lack of basic communication and presentation skills in the workplace will lead to inefficiency, wasted efforts, and possibly financial losses. That said, industry employers assume most professionals who graduate with a specific degree will have the technical expertise and knowledge to achieve the job. Thus, they seek professionals who possess the ability to communicate their findings with others in a productive, efficient manner [7]. Communication skills, especially presentation skills, is a significant determiner of success in the modern STEM and CM professional career, and thus should be nurtured effectively through academic programs [7].

\section{I.3. Literature Review}

Due to this recent increase in attention to changing expectations from practicing $\mathrm{CM}$ professionals, there is an urgent need to develop new skill sets throughout students' academic careers [18][22]. Nevertheless, successfully developing these skills in technical majors require innovative approaches, as these soft skills have not been precisely the focus of most STEM and CM programs in the past.

Additionally, as the demographics in the United States diversify and as CM student enrollment continues to grow, higher education institutions have struggled to adapt to the diversity of their student body needs [23]. Even though literature indicates that oral 
communication has been identified as a learnable skill and some institutions attempt to provide extracurricular communication skills training sessions, such training remain separate from the technical curriculum; moreover, most of the coursework is heavily skewed towards writing, which ultimately hinders active engagement [9]. Although communication-focused activities have recently been incorporated into engineering schools (motivated by ABET and other accreditations), some universities have not adopted these accreditations [24]. Thus, countless STEM undergraduate and graduate programs that are not ABET accredited are not required to incorporate communication development training into their curricula. Special attention must be placed in these programs to ensure students are developing sufficient skills to compete in the workplace. Engineering education, therefore, has to effectively add value beyond just teaching technical skills [25]. While teaching CM students how the physical world works are at the core of their education today, re-examining how institutions teach other necessary skills required to succeed is needed [26].

Studies have stresses how construction engineering education has been plagued with low engagement levels partially due to its timeworn pedagogical means and ineffective use of technology [27]. As Social Media is used by more than 40 million students, education programs and previous studies have tried to leverage this technology to support education [28]. The accessibility of Social Media tools, such as laptops, cell phones, tablets, among others, makes it extremely convenient and universal; thus, the number of student involvement in Social Media is on the rise [29]. Thus, utilizing this technology represents an effective platform for students as it increases involvement between peers, facilitates 
emotional support, promotes educational discussions and creative activities [30]. For instance, programs that have adapted alternative teaching techniques for teaching technical content, such as incorporating social media, result in higher student performance; thus, this medium offers valuable tools for teaching and collaborative learning [31]. Previous studies have also discussed the educational benefits of appropriating social media into learning contexts, suggesting that integrating social media in educational and learning environments may yield new forms of investigation, communication, collaboration and participation, identity work, or have positive cognitive, social, and emotional influence [32]. Other advantages of integrating Social Media in education is its versatility, as it allows the following of course lessons in any place and time, while also ideally engaging in course materials by sharing opinions and discussing problems with peers [33]. The use of Social Media has also been introduced in the medical field, where the integration of Social Media tools increased opportunities for cooperative and active learning [27], [30]. Regardless, cautionary use with these activities has been advised, as research also demonstrates that leveraging social media for learning has increased students' time spent on Facebook and ultimately negatively affected student grades [32],[34]. Even though this approach has not been previously used for educating CM students about communication and presentation skills, this medium shows a promising opportunity to explore and further advance students' skills.

Integrating other teaching techniques alongside other non-traditional tools, such as Virtual Reality, also constitute an alternative and innovative medium for education [35]. Previous studies have shown the effectiveness of these tools, as these state that using VR leads to 
better performance, offering a direct feeling of scenarios and events that are physically out of reach, and encourages training in safer environments, avoiding real potential dangers [36]. These immersive approaches also reduce time constraints related to commuting and physical inaccessibility, such as exploring areas beyond students' reach and potentially reduce ethical problems, as in the case of medical students performing "surgery simulations" [36]. Regardless of the field, VR immersive learning has promised an effective way of teaching technical content and provides a paradigm shift from previous approaches, as it permits all human senses to be involved [35]. While previous studies have focused on utilizing this technology to improve the way technical skills are taught, also taking advantage of this technology to enhance additional skills, such as soft skills, should be explored, especially in STEM and CM education.

In addition, certain studies have worked to improve students' communication skills through alternative approaches. A recent study conducted on undergraduate students evaluated a multimedia instructional approach to develop oral presentation skills in higher education. Through this implementation, feedback was obtained from the participants and was analyzed to reveal that oral presentation skills did improve significantly after the multimedia instruction [37]. Nevertheless, while this study was not conducted in STEM courses and only had undergraduate freshmen participation, incorporating similar techniques in STEM higher education throughout all academic levels, could help reduce the communication and presentation skills gap. 
Moreover, a recent study in the medical field introduced alternative teaching techniques to improve medical students' confidence, expertise in storytelling and achieve more successful presentations [38]. Their approach consisted of offering students communication exercises to allow them to engage with patients in a more effective manner. Then, through student feedback and evaluation surveys, their development was tracked [38]. Their results indicate that their alternative teaching techniques were effective teaching methods for this field. Moreover, this study can serve as an innovative model for how communication and presentation skill development activities can be incorporated for teaching and professional development initiatives at all levels of STEM education, including CM.

Studies vary in their approach to solve students' communication and presentation skills deficiency. Another study conducted at a NY university utilized lecture capture system to explore additional pedagogical use of educational technology. This study compared the self-perceptions of undergraduate communication/journalism and nursing students who used lecture capture technology for critiquing and analyzing their presentation skills with self-perceptions of students who did not use lecture capture technology. This study revealed students using innovative alternative approaches were more likely to apply what they learned when developing future presentations [39].

Therefore, previous studies indicate there is a promising opportunity to utilize innovative approaches to aid students in developing their presentation skills. Regardless, although many efforts and studies have been made to explore alternative learning techniques, there 
is no data-base information or studies that have implemented these techniques in construction management courses. Moreover, past studies have not collectively implemented various forms of alternative learning techniques. That said, this thesis focuses on enhancing FIU CM curricula by integrating three objective and innovative communication activities that make up for these students' skill gap; and explore new pedagogies that encourage the development of CM students' professional skills.

\section{I.4. Hypotheses}

This study seeks to evaluate the following hypotheses:

1. FIU STEM students' current communication skills are influenced by their sociodemographic profile.

2. FIU STEM students' lack of communication skills is not due to a lack of awareness on the skills' impact on their academic and professional success.

3. Incorporating communication skills activities in the form of lectures into CM courses' syllabi will improve FIU CM students' presentation skills.

4. Utilizing Virtual Reality (VR) technology in communication skills activities will influence FIU CM students' professional growth, specifically enhancing their body language.

\section{I.5. Methodology}

Figure 1 shows the research overview, where it is divided into five chapters.

Chapter 1 provides a thorough discussion of some of the background and motivation for this specific study. It presents the industry's perception of soft skills as well as students' 
perception of such and introduces the idea of implementing the much-required communication training into academic programs. This chapter also presents the thesis hypothesis proposed and proven throughout the research.

Chapter 2 consists of a benchmark survey administered to 327 STEM students currently enrolled in the College of Engineering and Computing at Florida International University. These students provided information regarding their current perceived level of presentation skills, their opinion of its relevance to their professional careers, as well as common practices when preparing for a presentation. This feedback allowed us to identify the main weaknesses and strengths across the FIU STEM student body, as well as address hypothesis 1.

Chapter 3 discusses the integration of three innovative communication skills training, including: (1) Lecture-Style Presentation Skills Training; (2) VR Presentation Simulation Training and; (3) Social Media Communication Skills Activity. Through these three activities, students learned the effectiveness of proper use of multimedia, techniques to engage audiences, and applying storytelling, control their emotions, among others. The study assessed the effectiveness of the activities by conducting peer-evaluations and analyzing the data through paired t-tests in SPSS and boxplots with line plots developed in RStudio. For this activity, data were collected from five different construction management courses, and so the research divided the results of these activities into three groups:

- Group A consists of results obtained from BCN5585: Sustainable Construction and BCN4570: A Sustainable Approach to Construction. 
- Group B consists of results obtained from BCN1013: Principles of Construction Management and BCN2253: Building Construction Drawing.

- Group C consists of results obtained from BCN3727: Construction Sitework and Equipment.

Chapter 4 consists of an Exit Survey distributed to 87 students from the five different construction management courses involved in this study. The exit survey provided relevant feedback into each activity's effectiveness and gauged the students' perception of which activity had more impact on their presentation and communication skills. The exit survey also provided the students' highlights and comments into the communication skills training, ensuring a thorough analysis of the different activities' effectiveness and acceptance.

Chapter 5 presents the summary of this study, the author's explanation, and analysis regarding the research, along with the study's limitations, contribution to knowledge, and recommendations for future work. 


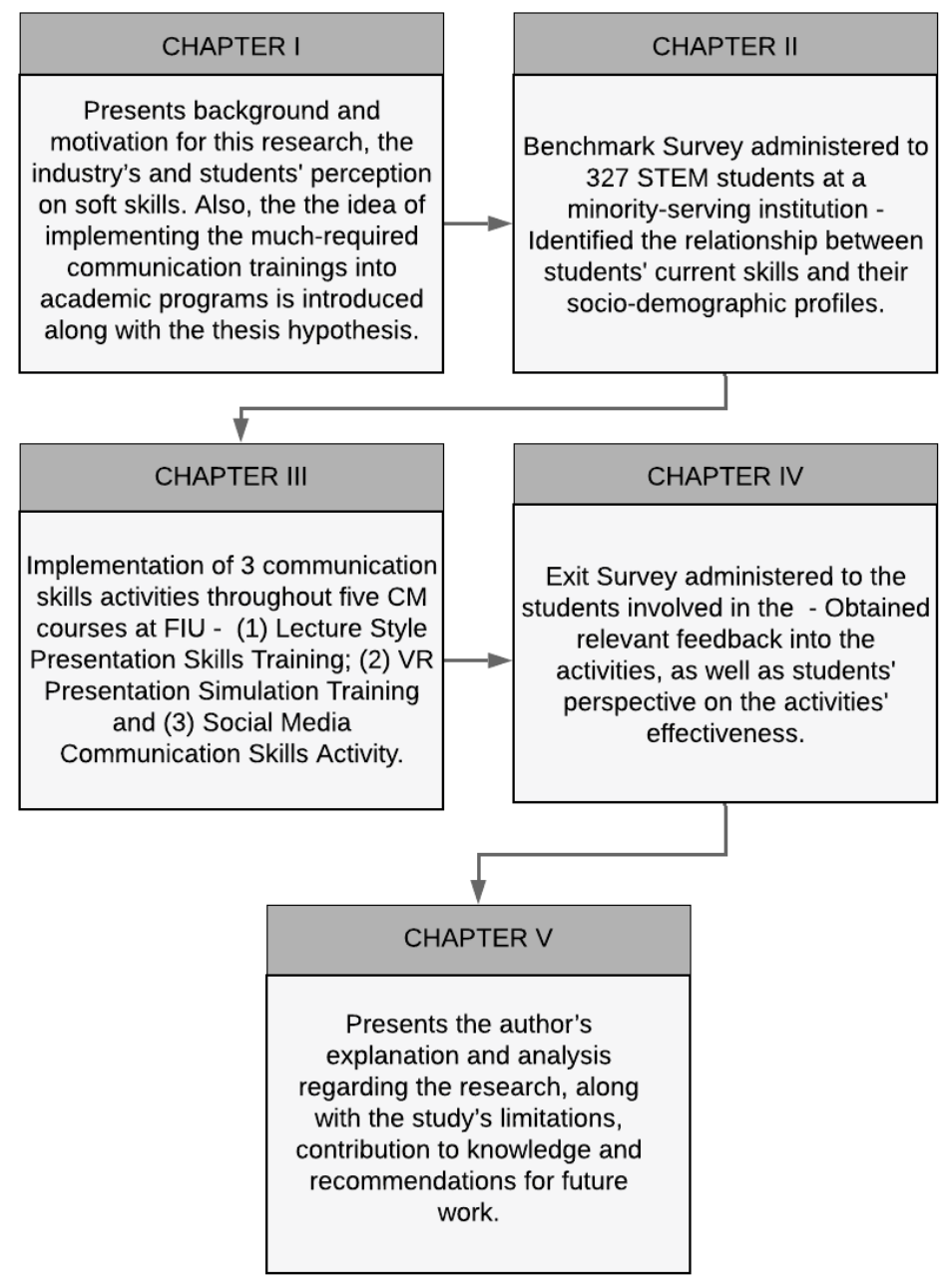

Figure 1. Research Overview 


\section{CHAPTER II}

\section{II.1. Creating a Benchmark for FIU STEM Students' Communication Skills}

Regardless of the specific field, effective communication skills are crucial to become competent professionals. Although these intangible qualities are often referred to as "soft skills", they are tightly coupled with professional performance and play an obvious and hard role in the success of any fresh graduate precisely those scholars perusing STEM careers [40]. Industry leaders often confirm the lack of such soft skill, stating that these graduates often lack the more intangible qualities, such as communication skills, when entering the workforce [40][41]. Despite a great deal of recent anecdotal evidence that communication is important to practicing engineers, no data-based information is available to help educators understand what specific communication skills STEM students lack and thus require further training and reinforcement. Thus, to understand and support students' communication and presentation skills at Florida International University, a benchmark survey was administered to 327 STEM students to understand their current status, priorities, and deficiencies in presentation skills. To this end, this chapter focuses on (1) understanding FIU STEM students' current presentation skills; and (2) analyzing correlations between FIU STEM students' socio-demographics and their presentation skills.

\section{II.1.1. Benchmark - Methodology}

This chapter addressed Research Hypothesis \#1 and \#2. Moreover, this chapter encompasses the communication/presentation preferences, understanding their current status, and then helping students in STEM to further develop their communication and 
presentation skill sets. This study consisted of a benchmark survey, distributed to 327 STEM students at FIU's College of Engineering and Computing. Through this survey, the author evaluated students' baseline presentation skills, to understand the importance of communication and presentation skills from the students' perceptions as well as their current self-assessment to such skills and their common presentation practices. The evaluations were conducted through Qualtrics, a web-based tool to conduct survey research, evaluations, and other data collection activities [42]. In the benchmark survey, students self-evaluated their strengths and weaknesses, as well as provided their knowledge on the fundamentals of presenting and presentation skill. Additionally, to understand the impact of students' socio-demographics on their presentation skills, an ordinal probit regression analysis was conducted. Through this analysis, the author determined which independent variable has a statistically significant effect on the dependent variable, as well to determine how well the model predicts it. For this model, the dependent variable was defined as Students' Current Skills, while the independent variables are Gender, Academic Level, International Status, Previous Communication Skills Training, Public Speaking Experience, First Generations, and Interest on Communication Skills Training. The ordinal probit regression model utilizes these parameters through the following equation:

$$
y_{i}^{*}=X_{i} \beta+\varepsilon
$$

\section{Equation 1. Ordinal Probit Regression Eq.}

Where $y_{i}{ }^{*}$ is a latent variable measuring the professional development of the ith participant; $X_{i}$ is a (k x 1$)$ vector of observed nonrandom explanatory variables; $\beta$ is a (k x 1$)$ vector of unknown parameters and; error factor $(\varepsilon)$ captures the reality that the Student Skills is not 
perfectly predicted by the regression equation [43]. Therefore, Student Skills, $y_{i}$ is determined from the model as follows:

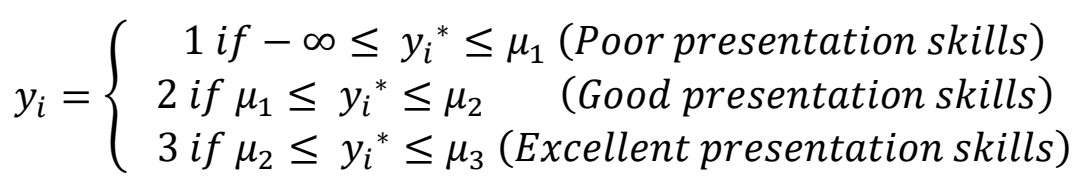

Equation 2. Ordinal Probit Regression

In Equation 2, the partial change in $y^{*}$ with respect to $X_{i}$ is $\beta_{\mathrm{i}}$ units. This implies that for a unit change in $X_{i}, y^{*}$ is expected to change by $\beta_{\mathrm{i}}$ units, holding all variables constant. Furthermore, the significance test uses the t-score to describe how the mean of the data sample with a certain number of observations (i.e., $n=327$ in the case of this study) is expected to behave [43]. Whereas the P-value indicates the confidence level, in terms of correlation, of each variable with the dependent variable. The confidence interval in the analysis is assumed to be $90 \%$ for this study; thus, the area under the curve (z) is obtained as 1.645 .

\section{II.1.2. Benchmark - Results}

Through the self-assessment survey, 327 STEM students at Florida International University self-evaluated their current presentation skills, of which $36 \%$ of respondents were female, $62 \%$ first-generation students, and 90\% non-native English speakers, as shown in Figure 2. Additionally, Figure 3 shows the distribution of the respondents' different engineering majors, where $20 \%$ is currently enrolled in electrical engineering, $19 \%$ in construction management, $16 \%$ in civil engineering, $13 \%$ in computer science, and so on. 


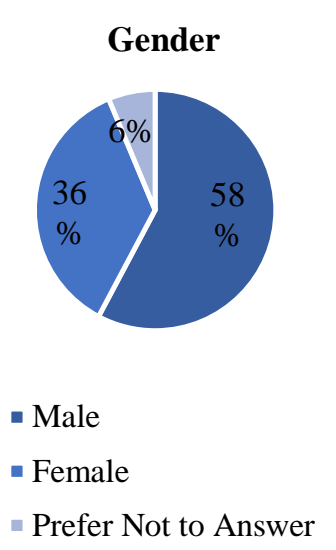

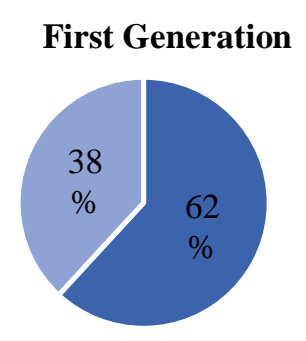

- First Generation Students

- Not First Generation Students
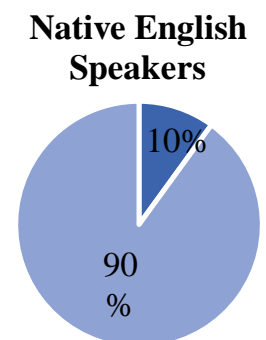

- Native English Speakers

- Non-Native English Speakers
Race

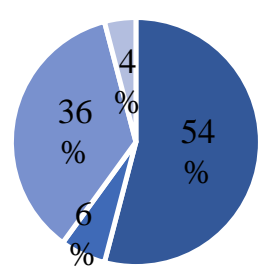

- Asian

- African American

- White

- Prefer Not to Answer

Figure 2. Respondents' Socio-Demographic Profile - Benchmark Survey, N=327

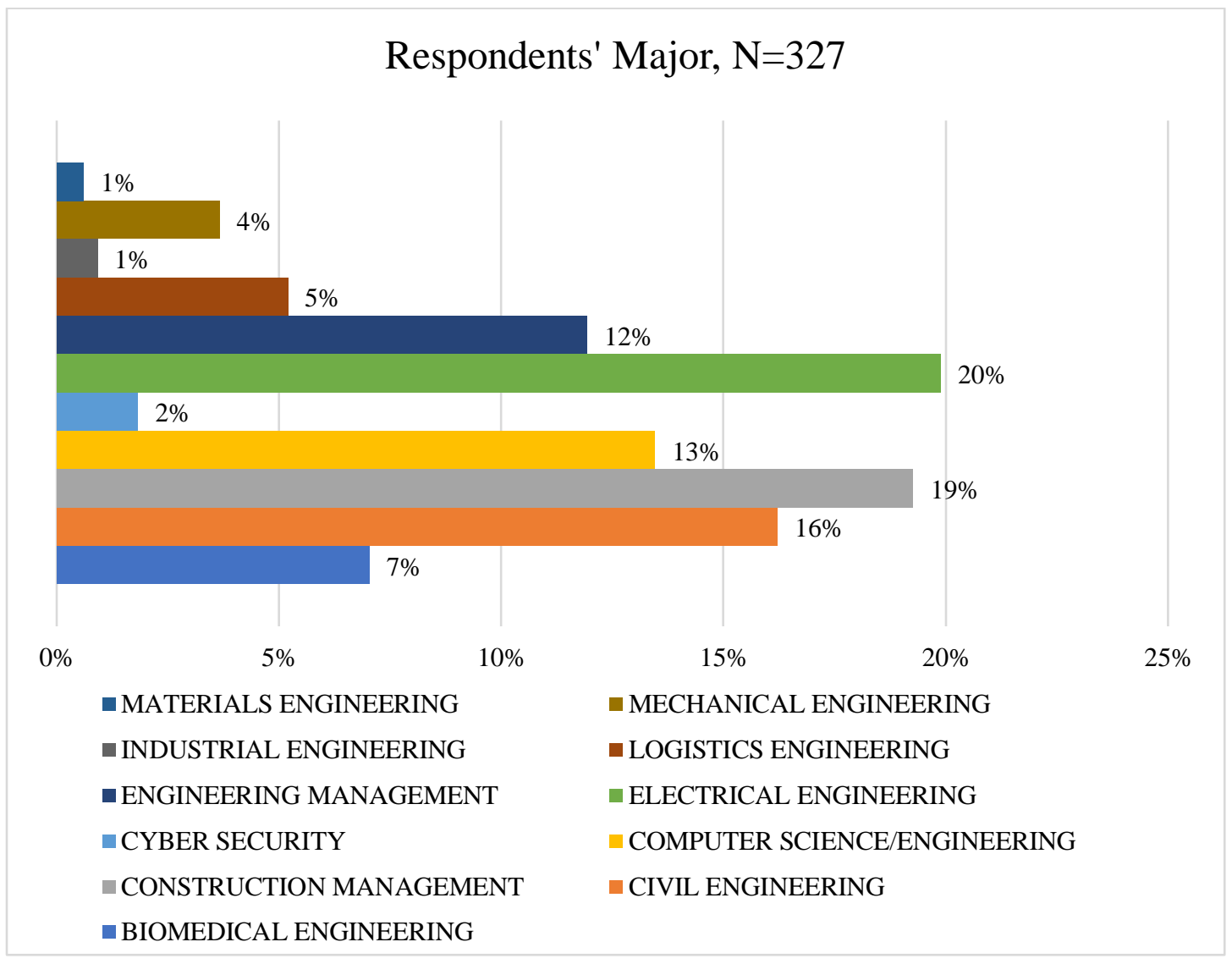

Figure 3. Respondents' Major, N=327 
The respondents were asked if they believed developing communication skills would help them advance in their professional careers, where $98 \%$ stated they believe that it would enhance their communication/presentation skills, while 2\% did not agree (See Figure 4). Since such a significant percentage is aware of the skills required to succeed, academic programs must ensure they are offering skill development opportunities to their entire student body to address these students' demands effectively. Additionally, respondents were asked to rate the importance of possessing presentation skills in their respective fields, based on a 5-point Likert Scale where 1 indicates unimportant, and 5 indicates highly important. Based on the results, 92\% of FIU STEM students consider presentation skills important in their field, with $22 \%$ indicating it is moderately important and $70 \%$ highly important, as shown in Figure 5.

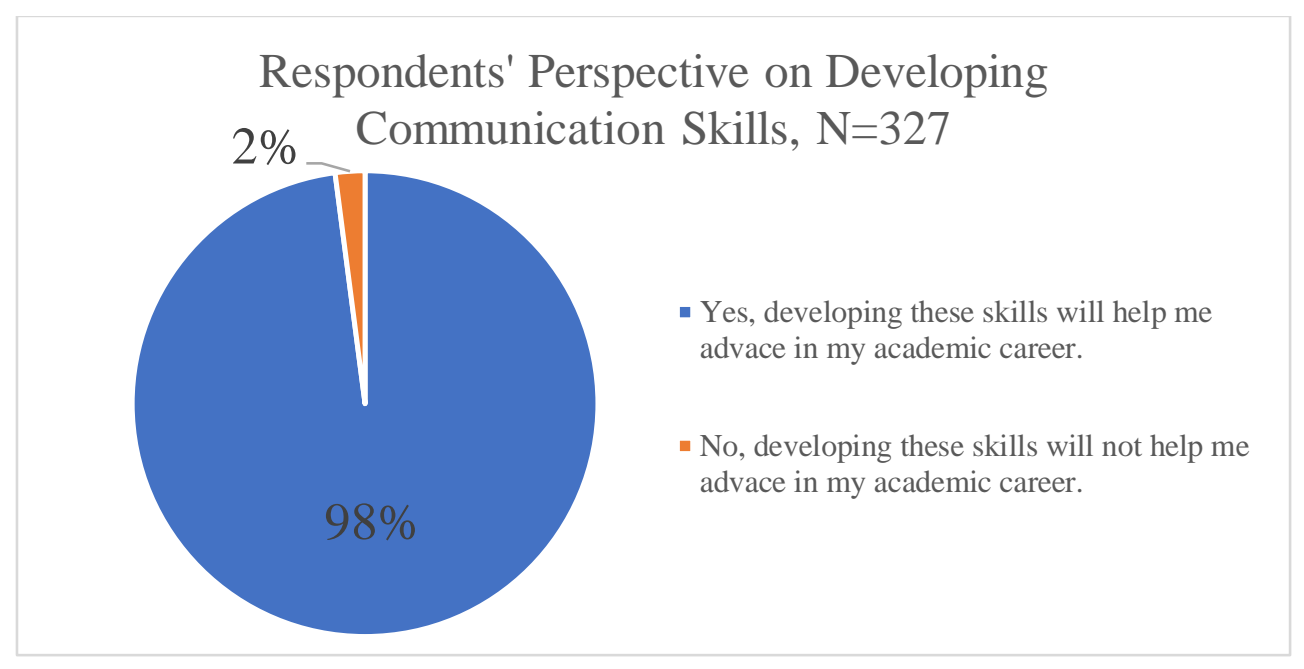

Figure 4. Students' Perspective on Developing Communication Skills, N=327 


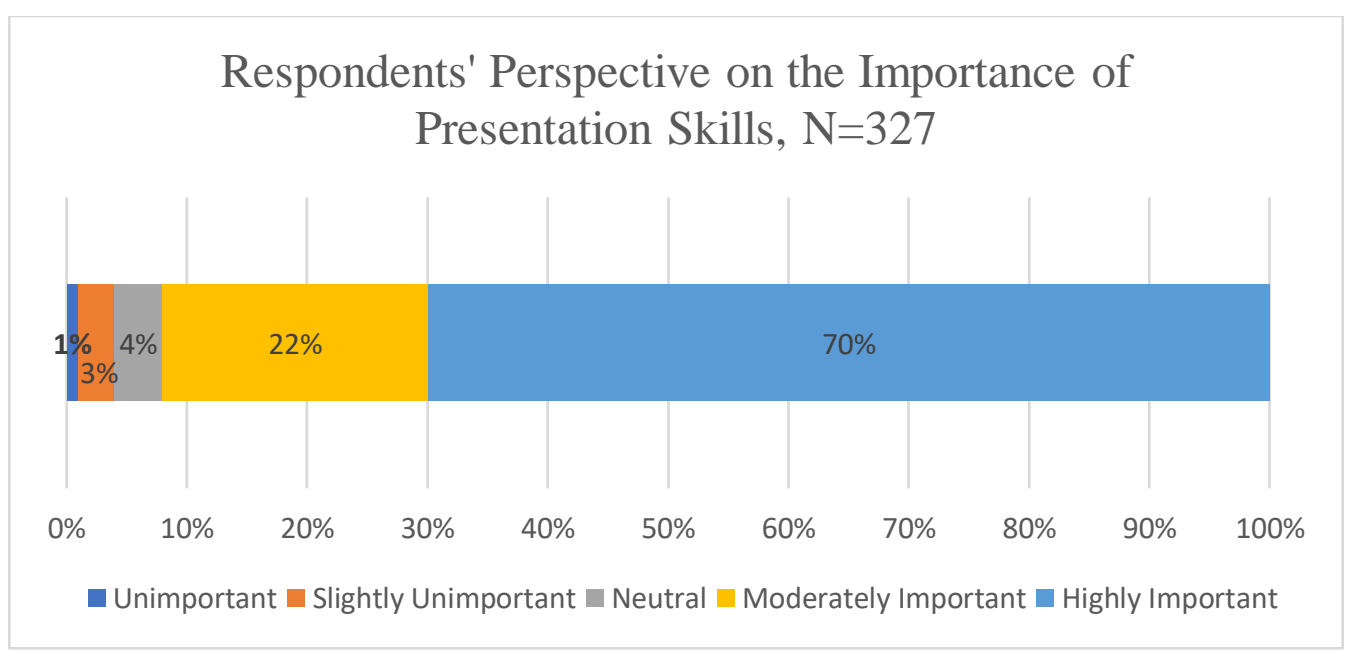

Figure 5. Respondents' Perspective on the Importance of Presentation Skills, N=327

FIU STEM students involved in the survey were also asked about their presentation preparation techniques. Based on the results, $75 \%$ of respondents take preparation measures before their presentation, stating that they usually rehearse their presentation performance, while 25\% do not prepare prior to presentations, as shown in Figure 6. Out of this $75 \%, 83 \%$ state they prefer practicing by themselves, while $17 \%$ rehearse in front of an audience (friends, colleagues, etc.). These results indicate students do acknowledge the importance of their presentation performance and strive to achieve better presentation performances, as most place a significant effort to successfully deliver them. 


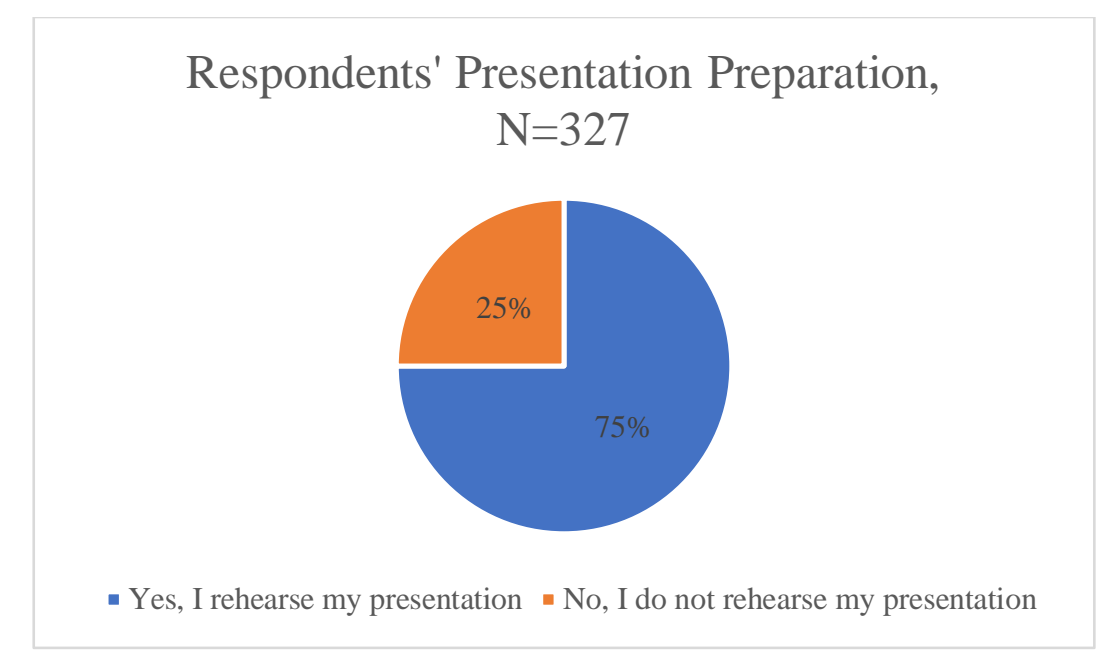

Figure 6. Respondents' Presentation Preparation, N=327

Moreover, the results of the students' self-ratings are shown in Figure 7. These results indicate that the majority of the students lack common presentation skills. The chosen evaluation criteria in this survey reflect the main presentation skills necessary to conduct effective presentations, such as delivery, body language, language skills, organization \& content, among others [15],[16]. Thus, results indicate FIU STEM students require reinforcement in these areas, as the average score for body language (BL) is 3.49 , language skills (LS) is 3.49, content preparation and organization (CP) is 3.88 , ability to engage audiences (EA) is 3.38, time management (TM) is 3.67, use of script support (SS) is 3.21, use of storytelling (S) is 3.29 and ability to control emotions (CE) is 3.57. Based on the student self-assessment responses (Figure 7), the areas that received the lowest average ratings were inability to include storytelling techniques (S), effectiveness to use script support (SS), as well as incompetence to engage audiences (EA). Students expressed that their presentation strengths were content preparation and organization $(\mathrm{CP})$ and time management (TM), yet these skills received a rating of approximately 3 , indicating that 
their strengths are still considered as underdeveloped. Therefore, results indicated that there is room for improvement and mastering all the different presentation criteria.

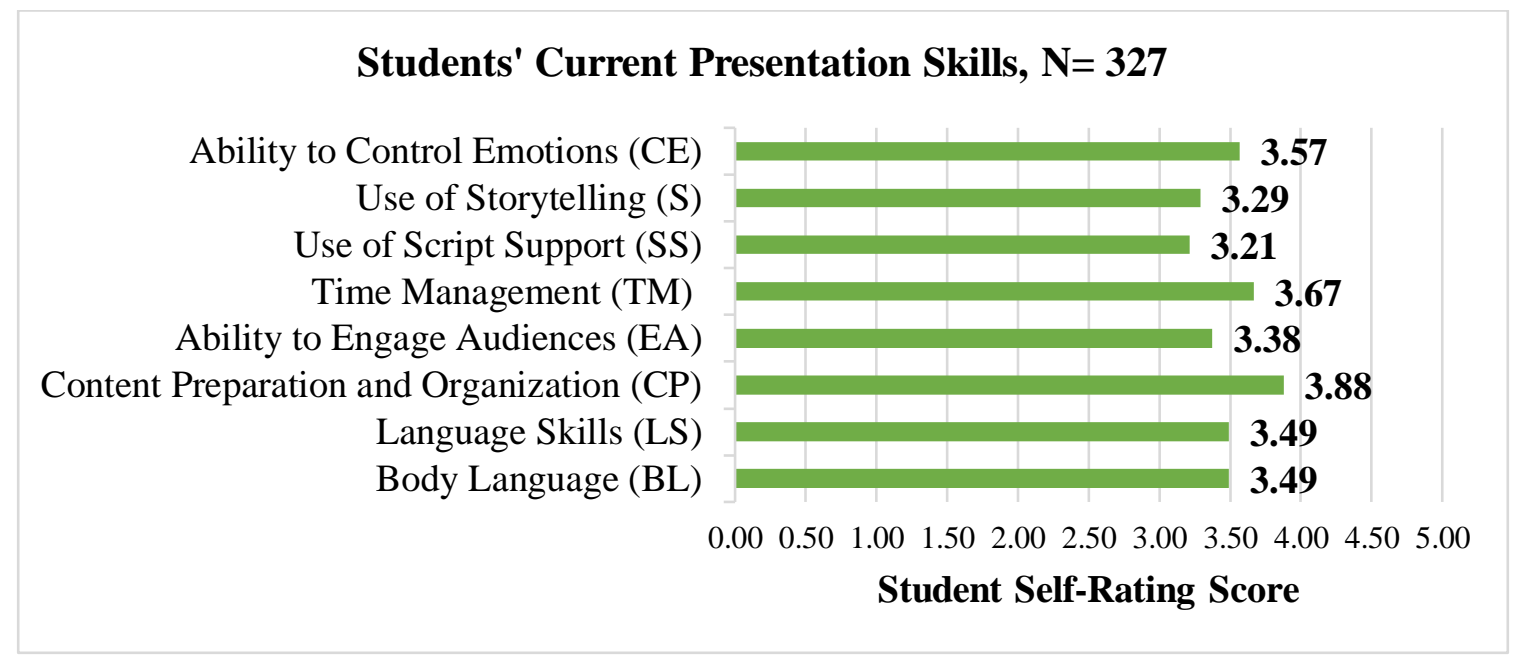

Figure 7. STEM Students' Presentation Skill Self-Assessment, N=327

Additionally, the students were surveyed on their perception on the importance of the different skills required to deliver a successful presentation. As shown in Figure 8, students rated $\mathrm{BL}, \mathrm{LS}, \mathrm{CP}, \mathrm{EA}, \mathrm{TM}, \mathrm{SS}, \mathrm{S}$, and CE, an average of 4.36, 4.43, 4.50, 4.31, 4.25, 3.51, 3.93 and 4.19, respectively. These results indicate that students are aware of the importance and impact of communication and presentation skills on their academic and professional success.

It is worth noting that while many students are aware of the vast impact that these soft skills will have during the professional careers, and strive to advance their presentation skills, results show their efforts are insufficient and their current preparation and skill- 
development methods are obsolete. Thus, these results support hypothesis \#2, stating that the reason that STEM students' lack presentation skills is not due to their lack of presentation knowledge or awareness in the importance of such, but rather lack of availability of structured trainings offered in higher education, as well as lack of opportunities to practice these skills. Offering the opportunity to successfully develop and nurture these skills during academic preparation, will potentially significantly impact FIU STEM students' academic careers and set the grounds for a promising professional career.

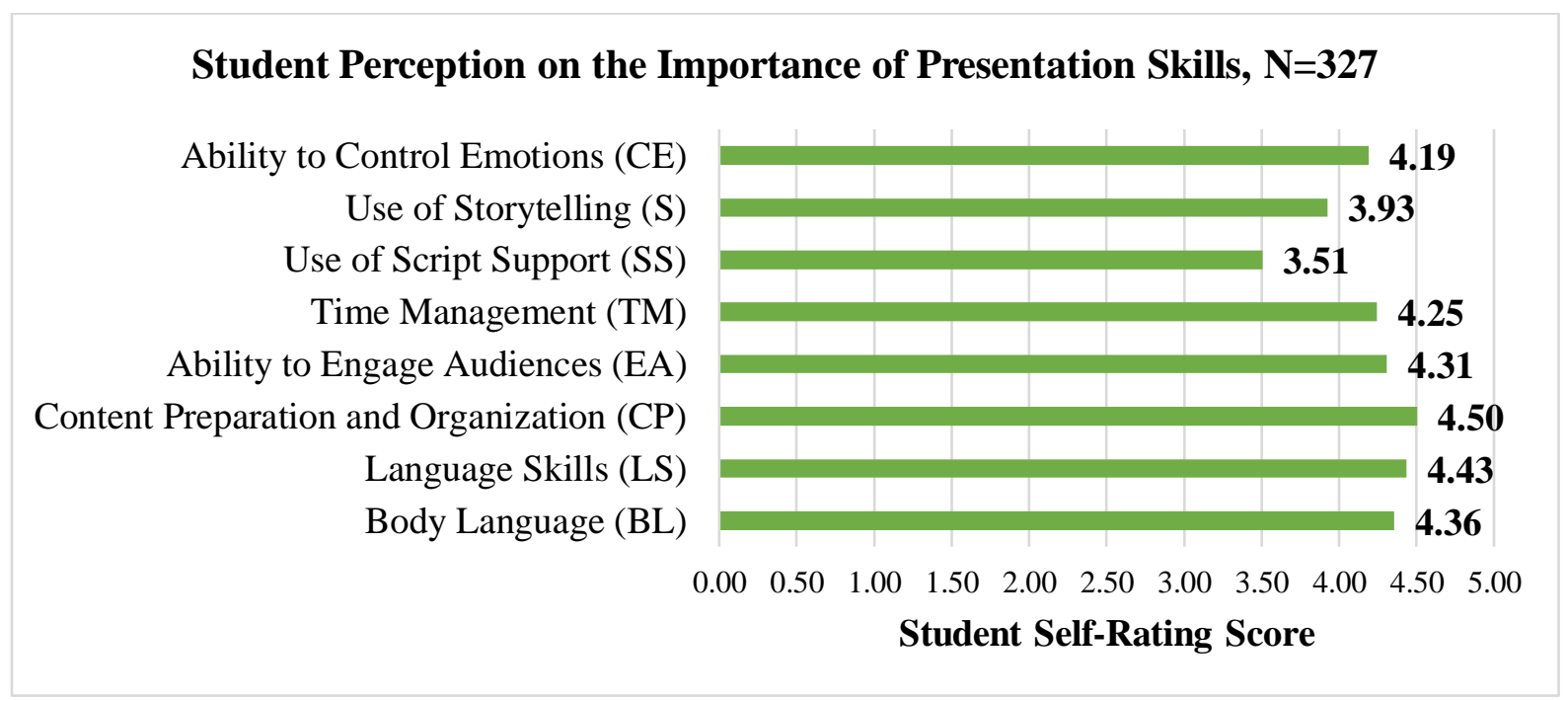

Figure 8. STEM Student Perception on Presentation Skill Importance, N=327

To address research hypothesis \#1, an ordinal probit model was conducted. Through this analysis, the author was able to analyze correlations between students' presentation skills and the socio-demographic profiles. Table 1 provides the estimated results of the student skills with a Pseudo $\mathrm{R}^{2}$ value of 0.55 . The regression coefficient values of Gender, Academic Level, International Status, Previous Communication Skills Training, Public Speaking Experience, First Generations, and Interest on Communication Training are 
$0.003,0.038,0.044,0.002,0.027,0.006$, and 0.062, respectively. Based on these results, it can be inferred that students' presentation skills are highly influenced by their sociodemographic profile and the statistical analysis in Table 1 reflects the below set of results:

- STEM students interested in communication skills training are more likely to achieve higher presentation skills than those who are not interested in trainings, as they are more motivated to participate in the activities and place more effort in ameliorating their presentation performance.

- International STEM students are more likely to possess higher presentation skills.

- Regarding gender, male STEM students tend to possess higher presentation skills. This could be due to the fact that STEM is a male dominated industry, thus male individuals could be more pressured to standout and be more competitive. Despite these suggestions, women have previously demonstrated superior talents in communication/presentation skills when properly guided through trainings.

- First-generation STEM students are less likely to have their presentation skills developed. This could be due to the fact that first generation students potentially face additional barriers than their counterpart, when in higher education programs. Additionally, these students potentially have less family influence to develop these soft skills outside their academic settings[44]. That said, and since first generation students need more trainings, higher education shall pose more focus on fostering such trainings to this student body to support their success in STEM.

- STEM graduate students are more likely to possess higher communication skills, possibly due to the fact that graduate students possess more academic knowledge, experience and different exposures than undergraduates. Thus, this could indicate 
that presentation experience and exposure can improve students' presentation skills. Thus, undergraduate programs could reinforce such skills through additional trainings incorporated into curricula.

- Students who have had previous communication skill trainings or public speaking experience are more likely to have better presentation skills. This could indicate that offering students different training activities and opportunities to practice their skills can in fact help further develop their presentation and communication abilities.

- $\boldsymbol{\mu}_{1}, \boldsymbol{\mu}_{2}$, and $\boldsymbol{\mu}_{3}$ are the coefficients of the ordered probit model with the values -6.8 , -3.8 , and 1.7, respectively. These values are the thresholds which reflect the predicted cumulative probabilities at covariate values of zero.

Regardless of their current skills, all STEM students, especially women and firstgeneration students, will benefit greatly from innovative communication skills activities that can successfully foster student's growth.

Table 1. Coefficients and P-Value from Ordered Probit Analysis

\begin{tabular}{|l|l|l|l|l|}
\hline Variables & $\begin{array}{l}\text { Coefficient } \\
(\beta)\end{array}$ & Std. Error & $\mathrm{Z}$ & $\begin{array}{l}\text { P- } \\
\text { Value }\end{array}$ \\
\hline $\begin{array}{l}\text { Indicator variable for Interest on Communication } \\
\text { Training } \\
(1 \text { if respondents are interested, 0 otherwise) }\end{array}$ & 1.537 & 0.82 & 1.87 & 0.062 \\
\hline $\begin{array}{l}\text { Indicator variable for International Status } \\
(1 \text { if respondents are International, 0 otherwise })\end{array}$ & 2.36 & 1.17 & 2.01 & 0.044 \\
\hline $\begin{array}{l}\text { Indicator variable for Gender } \\
(1 \text { if respondents are female, 0 otherwise })\end{array}$ & -2.95 & 0.9 & -2.98 & 0.003 \\
\hline $\begin{array}{l}\text { Indicator variable for First-Generation } \\
(1 \text { if respondents are first generation students, } 0 \\
\text { otherwise })\end{array}$ & -4.48 & 1.62 & -2.76 & 0.006 \\
\hline $\begin{array}{l}\text { Indicator variable for Degree } \\
(1 \text { if respondents are undergraduate, 0 otherwise })\end{array}$ & -1.55 & 0.74 & -2.08 & 0.038 \\
\hline
\end{tabular}




\begin{tabular}{|l|l|l|l|l|}
\hline $\begin{array}{l}\text { Indicator variable for Previous Communication } \\
\text { Training } \\
\text { (1 if respondents are not previously trained, 0 } \\
\text { otherwise) }\end{array}$ & -4.18 & 1.33 & -3.13 & 0.002 \\
\hline $\begin{array}{l}\text { Indicator variable for Public Speaking Experience } \\
(1 \text { if respondents are not experienced, 0 } \\
\text { otherwise) }\end{array}$ & -1.75 & 0.79 & -2.21 & 0.027 \\
\hline $\boldsymbol{\mu}_{1}$ & -6.8 & 1.82 & & \\
\hline $\boldsymbol{\mu}_{2}$ & -3.8 & 1.24 & & \\
\hline $\boldsymbol{\mu}_{3}$ & 1.7 & 1.17 & & \\
\hline
\end{tabular}

\section{II.2. Chapter Review}

While the vast majority of FIU STEM students acknowledge the essential aspects of delivering successful presentations and establishing proper communication, a significant percentage of the STEM student body does not believe they possess the necessary skills to do so. Results indicate that the main communication weaknesses across the different STEM majors are the inability to include storytelling techniques, engage audiences, and prepare successful scripts. Regardless, all students believed their overall skills were below average, indicating there is sufficient room for improvement. Additionally, results indicate that FIU female, first-generation, and undergraduate students are less likely to possess adequate presentation skills, which indicates these specific groups should be provided with alternative communication training techniques to ensure proper development. While $98 \%$ believe communication skills are critical for their professional success, and $75 \%$ believe they require presentation skills specifically, only a small fraction of the students believe they do not need any reinforcement in this area. This implies that current communication teaching techniques within FIU have not been successful at preparing its students with the necessary tools; thus, new alternative learning techniques should be provided within the educational programs. 


\section{CHAPTER III}

\section{III.1. Implementation of Three Communication Training to Nurture CM Students'}

\section{Soft Skills}

The growing challenges and increasing complexity of today's construction projects demand competent and capable construction managers. Thus, CM professionals must seek to master various skills that expand beyond the technical aspects [7]. This is especially true in this new era of technology and information, where competition is at an all-time high, and technical skills are rapidly becoming a commodity that can be obtained anywhere[3],[25]. Moreover, while evidence suggests that communication skills are critical to CM practices, studies report that these skills are being inadequately developed in educational courses nationwide [18]. The engineering education, therefore, must also focus on more than just teaching technical skills [25],[7].

This chapter addresses hypothesis \#3, and \#4, and describes the implementation of three innovative educational training, which nurtured FIU CM students' professional skills. The students involved in this study are from five different upper and lower-level courses, which include both undergraduate and graduate students. The five courses that implemented this activity are BCN4570 Sustainable Approach to Construction, BCN1013 Principles of Construction Management, BCN2253 Building Construction Drawing, BCN5585 Sustainable Construction, and BCN3727 Construction Sitework and Equipment, which are all offered at the College of Engineering and Computing. These courses will take part in the following communication skills training: (1) Lecture Style Presentation Skills Training; (2) VR Presentation Simulation Training; and (3) Social Media Communication Skills Activity. As the data obtained differs between the courses involved, the results of the 
activities are divided by groups. Group A consists of results obtained from BCN5585 and BCN4570, Group B consists of results obtained from BCN1013 and BCN2253, and Group C consists of results obtained from BCN3727.

\section{III.1.1. Activity 1 - Lecture Style Presentation Skills Training}

Due to this recent increase in attention to changing expectations from practicing STEM professionals, there is an urgent need to successfully develop new skill sets throughout students' academic careers [18]. Thus, the activity consists of a lecture-style communication skills training on Construction Management students' presentation skills. This lecture-style communication skills training will offer students the opportunity to enhance their presentation performance, improve their confidence and overcome common presentation issues, such as glossophobia, unpreparedness, ineffective visuals, inappropriate content, distracting body language, lack of dynamism, etc. The training also involved valuable information regarding emotion control techniques, methods of delivering complex information to diverse audiences, and effective visualization techniques for successful presentations. Since such training is usually part of extracurricular activities, one of the main goals of this approach was to integrate the training into the course work; therefore, each student was obliged to attend the training (as shown in Figure 9) as it was embedded as one lecture into each course's schedule. 


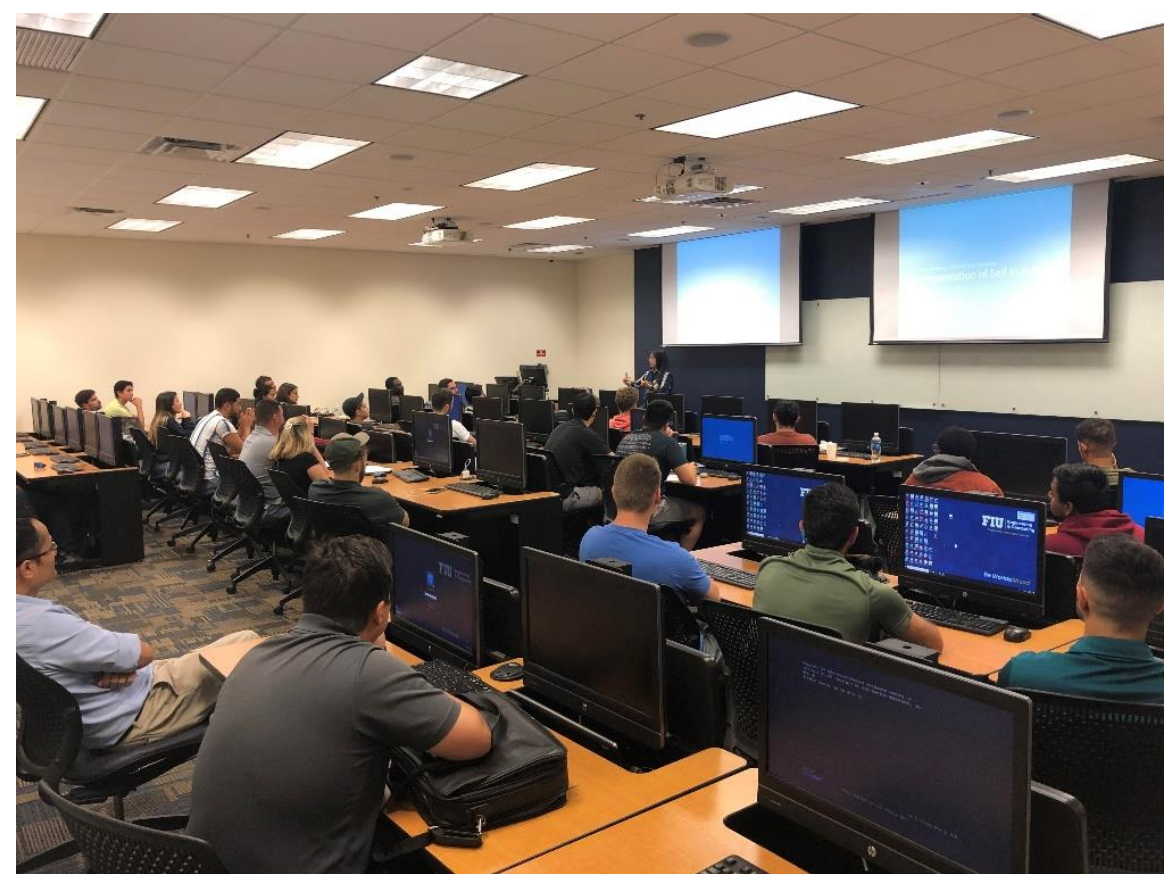

Figure 9. Lecture-Style Communication Skills Training

\section{III.1.2. Activity 2 - VR Presentation Simulation Training}

To prepare successful and competent construction managers, CM education must adapt and shift to more innovative learning techniques that allow aspiring CM professionals to grow professionally. For this reason, this activity consists of a VR-based presentation simulation offered to FIU CM students. This Virtual Reality (VR) presentation simulation training, consisting of semi-realistic virtual environments, in which students immerse in presentation scenarios to rehearse and improve their presentation skills. During this activity, students were required to choose a specific environment, such as a hotel conference room, a theatre, small to large classrooms, business meeting rooms, and the different criteria, thus obtaining personalized sessions for each student. The training was offered at the BEIL LAB at FIU - Engineering Center. In this activity, students participated in VR Presentation Simulation Trainings, a required portion of their courses' syllabi. 
Through an online portal, students could reserve a private 20 -min session to utilize the VR gear and participate in the training. The VR Simulations were conducted through Virtual Orator, a presentation simulation software that allows users to immerse themselves in various semi-realistic environments and rehearse in front of realistic and interactive audiences, as shown in Figure 10. The software also provides valuable feedback, such as the percentage of time spent with appropriate or inappropriate eye contact, length of presentation, and length of presentation slides.

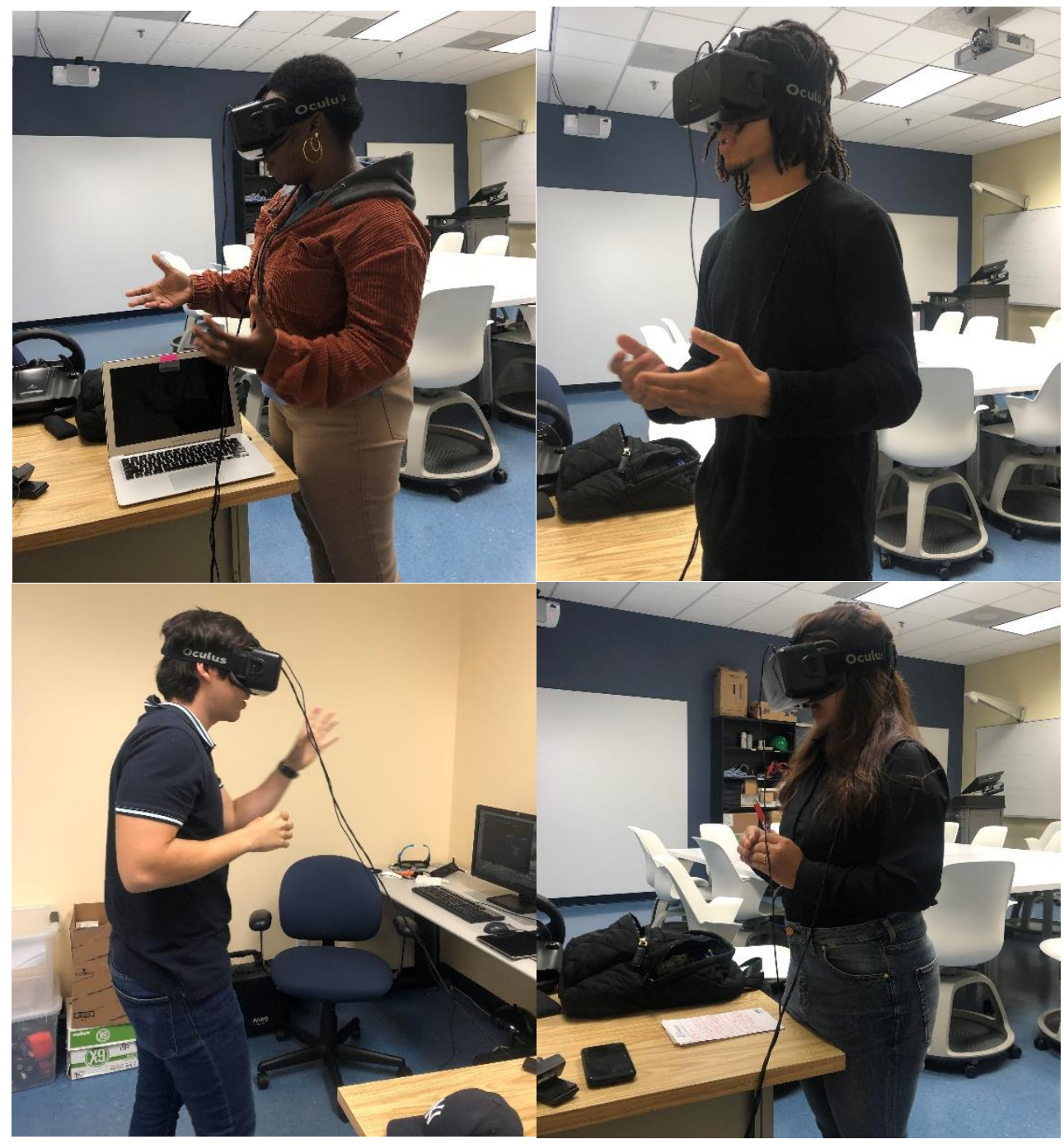

Figure 10. Students in the VR Presentation Simulation Sessions 
Additionally, the software allows users to personalize each session by indicating the type of audience desired, the level of attention of the audience throughout the simulation, and level of noise/disturbance within the audience, amongst others. During the training, students uploaded their presentation slides and practiced their presentation performance in different semi-realistic presentation environments. Students were required to choose a specific environment, such as a hotel conference room, a theatre, small to large classrooms, business meeting rooms, and the different criteria, thus obtaining personalized sessions for each student, as shown in Figure 11.

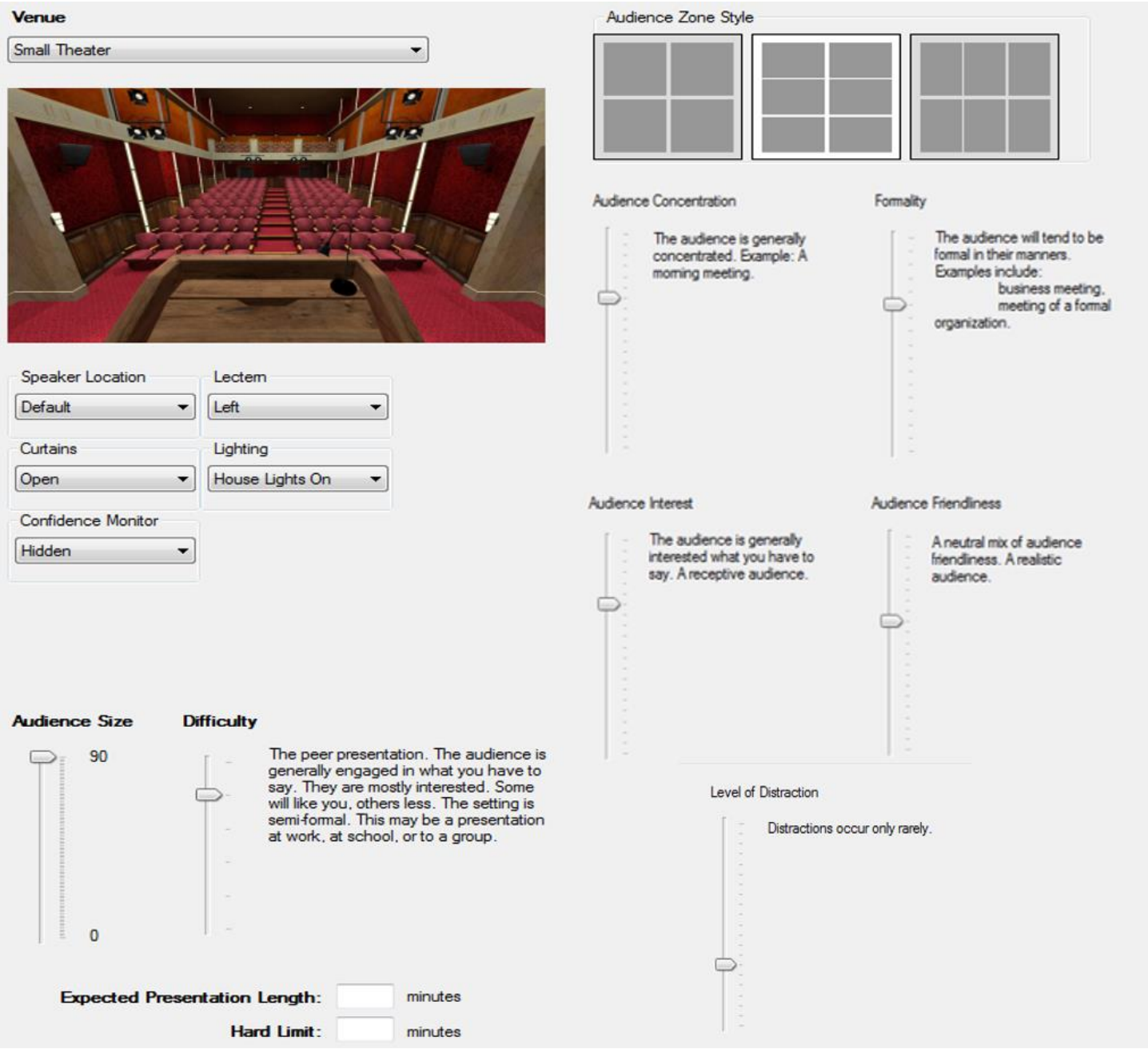

Figure 11. Virtual Orator Session Settings 


\section{III.1.3. Activity 3 - Social Media Communication Skills Activity}

To offer additional informal learning training, students participated throughout the semester, in a Social Media Communication Skills Activity. This activity consists of an online community called "Soft Skills for Construction Managers" created to offer an opportunity to engage with peers and professionals. Through this learning platform, students can share their insight, experiences, and relevant communication information in the form of videos, links, images, TedTalks, and much more, as shown in Figure 12. This activity seeks to broaden the students' reach into communication skills information and open the opportunity for insightful discussions regarding the importance of communication skills in their professional careers. Students were encouraged to share tips, advice, and insight into presentation/communication skills, in the form of posts, images, videos, links, etc.

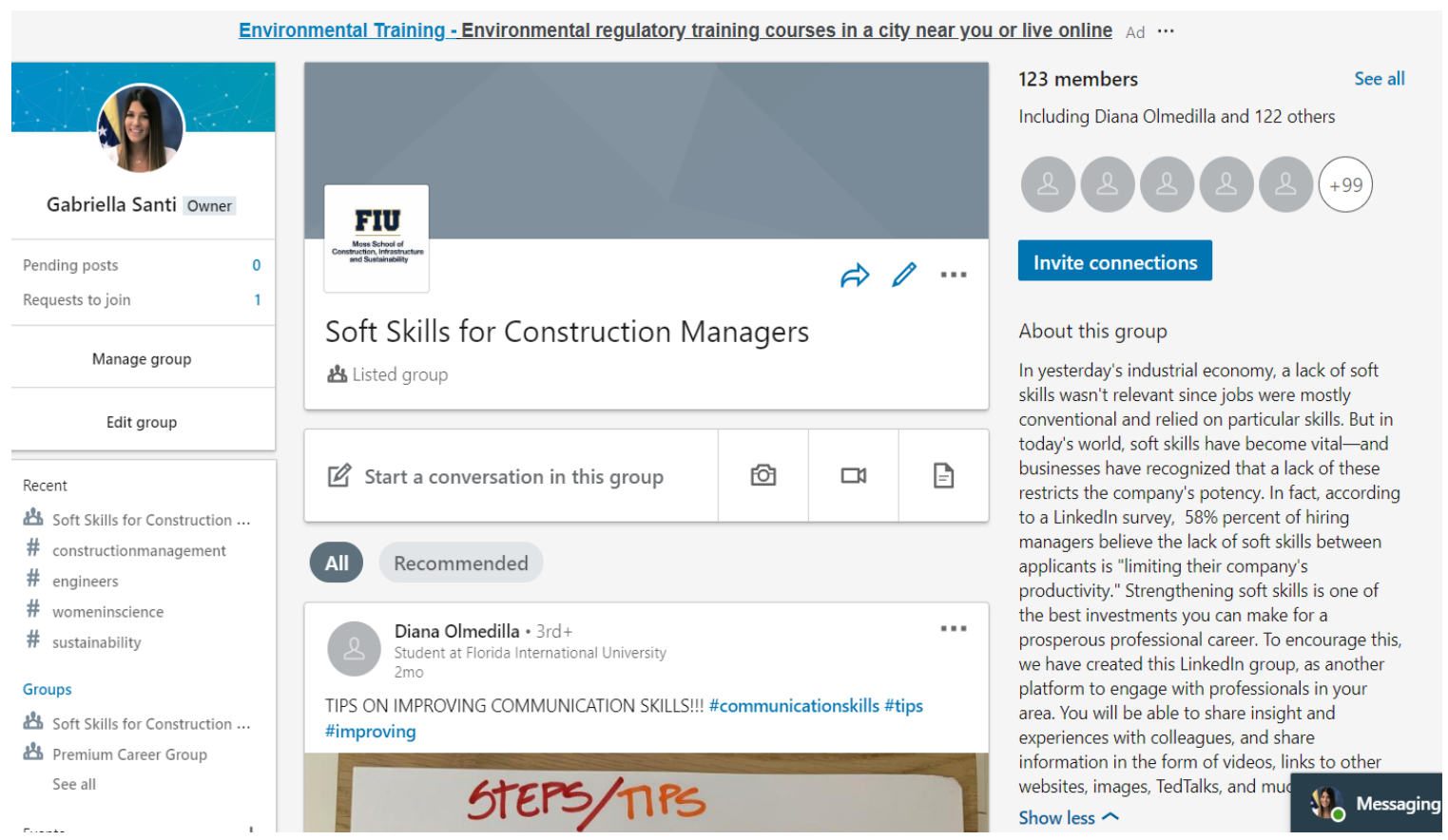

Figure 12. LinkedIn - Soft Skills for Construction Managers Group 
A total of 124 students participated in this activity, where they shared relevant information through the LinkedIn group "Soft Skills for Construction Managers". Based on this activity, a total of 187 different posts where shared, consisting of hand-made flowcharts, YouTube videos, TedTalks, links to external sites, images, and written entries sharing personal experiences and stories. Most of the content consisted of mediums to improve body language, reduce nervousness, balance proper eye contact, and deliver presentations with confidence (See Figure 13 Error! Reference source not found.and Figure 14).

Figure 13. Student Participation into Activity 3 


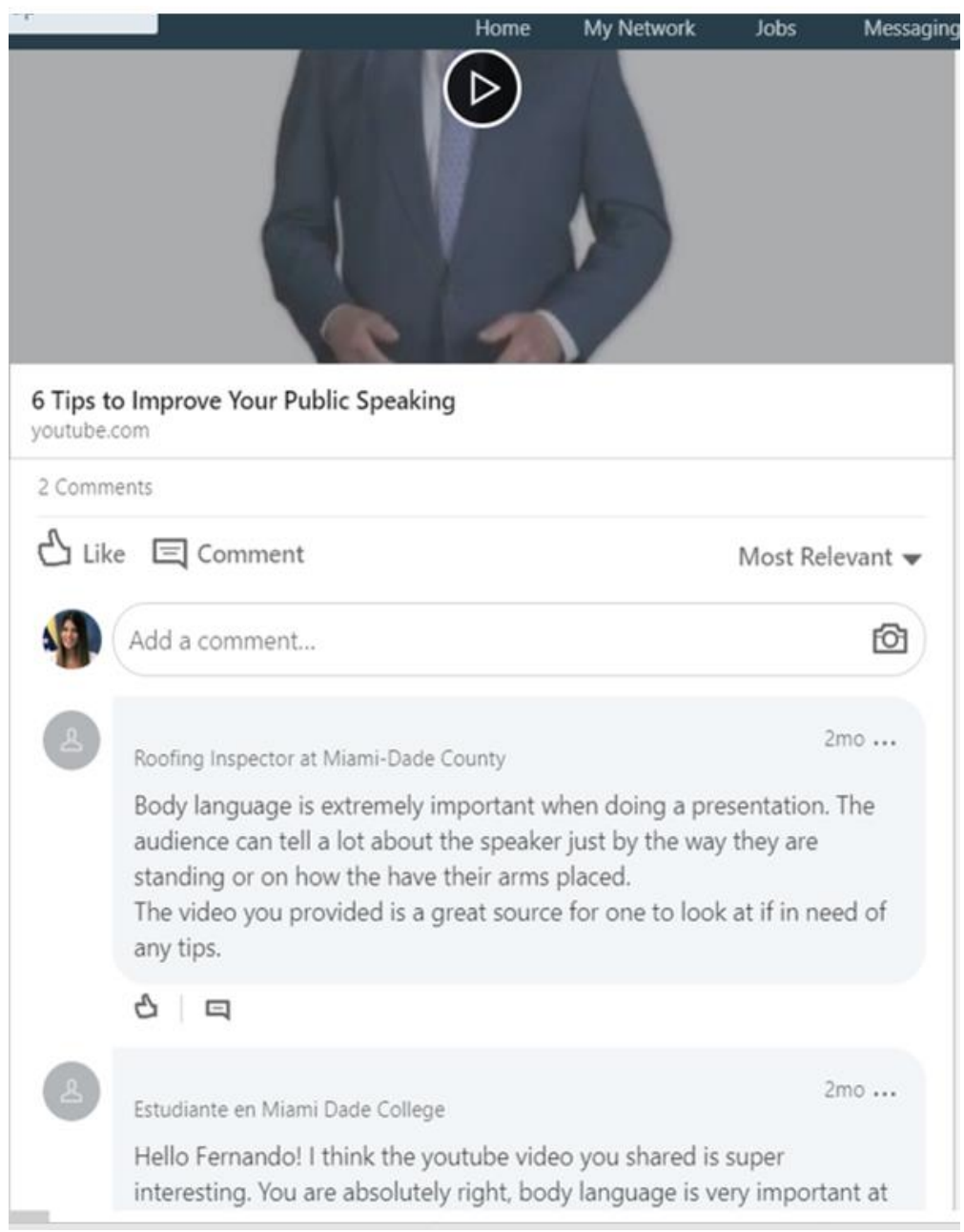

Figure 14. Student Participation into Activity 3

This type of activity offers students an opportunity to reinforce their skills through informal approaches. Students who participated in the activity potentially obtained multiple benefits, such as:

a. Critical Thinking Skills: posts are open-ended and allowed for the sharing of different points of view regarding the importance of these skills.

b. Individual and Team Learning: students had the opportunity to conduct individual research online regarding soft skills, allowing them to reflect and analyze these skills, while also encouraging them to share and discuss with their fellow 
peers. Students provided their personal views and discussed their perception of why specific skills were more relevant, challenging to master, and so on.

c. Increased Interaction: Although students were required to participate in specific course activities, their participation and involvement in the group were not for a specific period in the semester, but instead lasted the entire semester. Students could get notifications when other peers posted content, increasing their exposure to new ideas, concepts, among others. This extended interaction time also allowed students to reflect, absorb and create proper responses to other students' posts.

d. Democratic Exchanges: While during in-class sessions, certain students might not participate due to more introverted personalities, this social media activity offered a platform where all students have a voice and opportunity to interact.

e. Resource: Students involved in the activity increased their researching skills, encountering, and filtering through multiple online resources.

\section{III.2. Implementation of Activities - Methodology}

Amidst the first weeks of the Fall 2019 semester, each of the courses' instructors introduced Training 1 - an in-class guided Lecture-Style Communication Skills Training, which was conducted by a faculty in the FIU communication department. This faculty tailored the presentation to address how communication/presentation could be used and advanced in construction management. Since such training is usually part of extracurricular activities, one of the main goals of this approach was to integrate the training into the course work; therefore, each student was obliged to attend the training as it was embedded into the course schedule. 
Following Training 1, the students participated in Training 2 - VR Presentation Simulation Training, as shown in Figure 16. Through an online portal, students enrolled in different 20-min time slots for their individual VR sessions. These were required to upload their presentation slides and rehearse their presentation performance in semi-realistic environments. After each session, the students' presentation performance was analyzed through the software, obtaining relevant information regarding their eye-contact balance, and their time management skills. Finally, throughout the academic semester, students in all five courses were required to participate in Training 3-Social Media Activity, an online LinkedIn community, where they would share relevant information regarding communication skills. Students were encouraged to interact with their peers through this online platform while distributing and absorbing the information available online.

To analyze the effectiveness of the activities, each student from the aforementioned courses was required to conduct an in-class presentation related to the coursework where they also received peer-evaluations on their presentation skills, based on performance, delivery, body language, and other criteria, as shown in Figure 15. The chosen evaluation criteria reflect the primary presentation skills necessary to conduct effective presentations, such as delivery, body language, language skills, organization \& content, among others, as shown in Figure 15 [15],[16]. Peer-evaluations were chosen as a measure, as it is an effective quality assurance measure in many contexts, including science, business, and education and is considered more extensive than other common evaluation mediums [45],[46]. Peerevaluations have been shown to provide many advantages in STEM, including getting 
students to think about the exercise more deeply and seriously, and recognizing others' viewpoints and criticism [7].

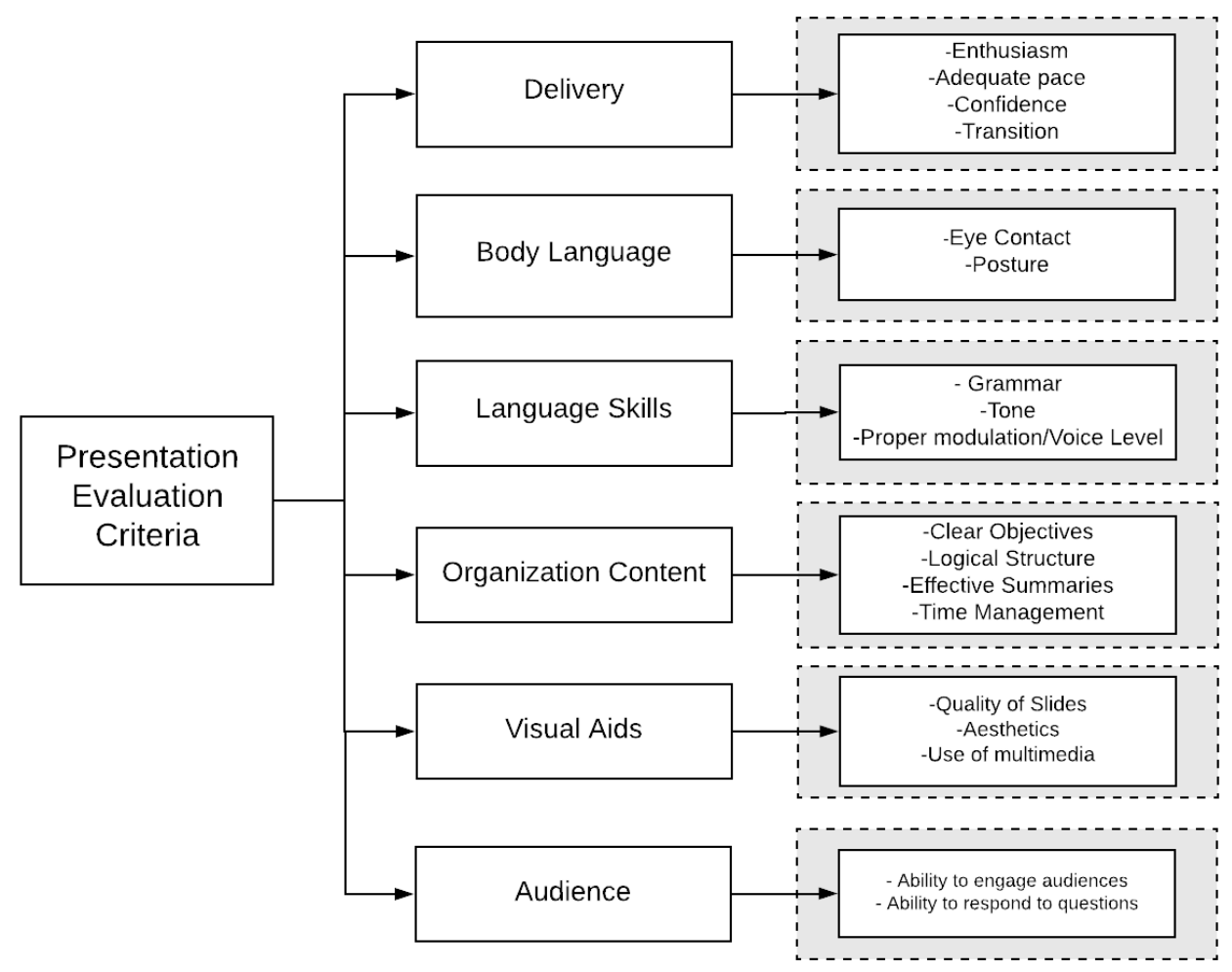

Figure 15. Presentation Evaluation Criteria

The proposed activity created an engaging educational environment that enhanced CM students' communication and presentation skills, thus honing their professional development. Their participation in the training increased their confidence, improved their performance and engagement, and allowed them to develop sufficient skills to convey technical information to diverse audiences. The data obtained from the survey and peer and self-evaluations allowed the authors to evaluate the activity's impact and acceptance, identify the students' strengths and weaknesses, and evaluate their professional development and growth. The data obtained was analyzed and compared through Paired 
T-Tests in SPSS and Boxplots with Line plots in RStudio. Results from the different courses are presented in the following sections.

As aforementioned, the results were divided into three groups as the data and peerevaluations obtained differed between courses. Group A was able to assess Activity 1 and 2's impact as it obtained peer-evaluations before and after each activity. Group B allowed to assess the three activities' impact by obtaining peer-evaluations at the beginning of the semester, and at the end of the semester, posterior to the activities' implementation. Group C provided peer-evaluations conducted at the end of the semester, after the implementation of the activities, as well as faculty evaluations measuring the students' presentation skills.

At the beginning of the Fall 2019 Semester, Group A and B conducted in-class presentations where the students were peer-evaluated based on their presentation skills. Then, after the implementation of Activity 1 in October, Group A conducted a second inclass peer-evaluation. Consequently, Activity 2 was implemented throughout the courses, and Group A conducted its third peer-evaluation of the semester. Next, Activity 3 was implemented, and at the end of the semester, Group B and C conducted their final in-class peer-evaluations. 


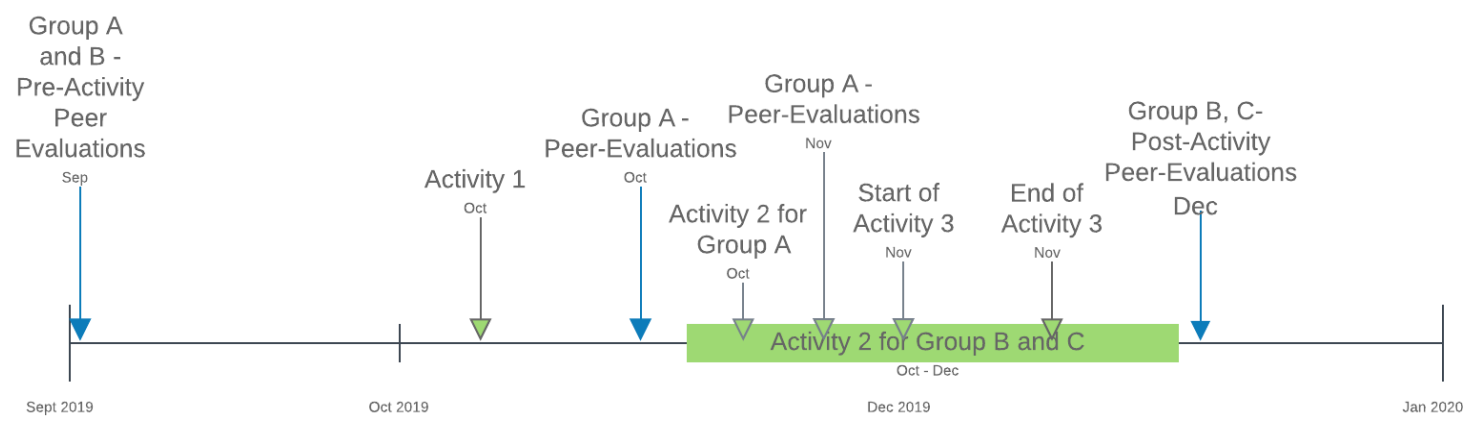

Figure 16. Timeline of Presentation Skills Activities

\section{III.3. Results for Group A}

\section{III.3.1. Results for the Peer-Evaluations of Activity 1 for Group A}

To assess the results of Activity 1, the students from Group A were asked to evaluate their peers' first presentation prior to their involvement in the activity. Through a 5-point Likert Scale, where 1 indicated extremely poor skills and 5 indicated excellent skills, the students rated their classmates on their presentation's delivery, body language, language skills, organization and content, visual aids, and ability to engage audiences. After carrying out the Lecture-Style Presentation Skills Training, students were required to conduct their second in-class presentation, where they received additional peer evaluations. Both peerevaluations were compared and analyzed using paired T-tests. A paired T-test is a parametric test in which assumptions are made about parameters of a distributed population from which a sample is drawn. Through this analysis, the authors analyzed the mean difference between the two data sets before and after the Activity 1 . A confidence interval of $90 \%$ was set for this analysis. Then, the obtained data were also graphically represented 
using box plots with line plots, which provides the correlation of each students' improvement or decline throughout the Lecture-Style Communication Skills Activity.

Based on these results, it can be concluded that the P-value for all the variables is less than 0.05 , indicating there is a significant difference in the means of the two data sets (i.e., preactivity results and post-activity results). As shown in Table 2, the mean difference for each variable has a negative sign, indicating that the students did in fact improve their different presentation skills through Activity 1.

Table 2. Paired T Test Results for BCN5585/BCN4570 - Activity 1

\begin{tabular}{|l|l|l|l|c|c|}
\hline & \multicolumn{1}{|c|}{ Mean } & Std. Deviation & \multicolumn{1}{c|}{$\mathrm{t}$} & $\mathrm{df}$ & Sig. \\
\hline Delivery & -.812656 & .6137 & -7.49 & 34 & .000 \\
\hline Body Language & -.872632 & .6669 & -7.402 & 34 & .000 \\
\hline Language Skills & -.511041 & .4690 & -7.37 & 34 & .000 \\
\hline Organization \& Content & -.75655 & .52213 & -7.113 & 34 & .000 \\
\hline Visual Aids & -.76531 & .59266 & -5.396 & 34 & .000 \\
\hline Audience & -.710060 & .63625 & -2.223 & 34 & .034 \\
\hline
\end{tabular}

Additionally, to compare and analyze the results, boxplots were developed through RStudio to graphically represent the respondents' development based on the in-class training provided. As shown in Figure 17, the students experienced significant growth in their ability to: (1) engage audiences; (2) use visual aids; (3) organization and content skills, (4) deliver successful presentations, among others. This indicated that the in-class communication training successfully improved students' presentation skills. It is also worth noting that some skills, such as overall language skills, did not seem to significantly benefit from the training, represented by the downward slope of the line plots in Figure 17 and thus, possibly require additional innovative training methods to observe a significant change in students' performances. 

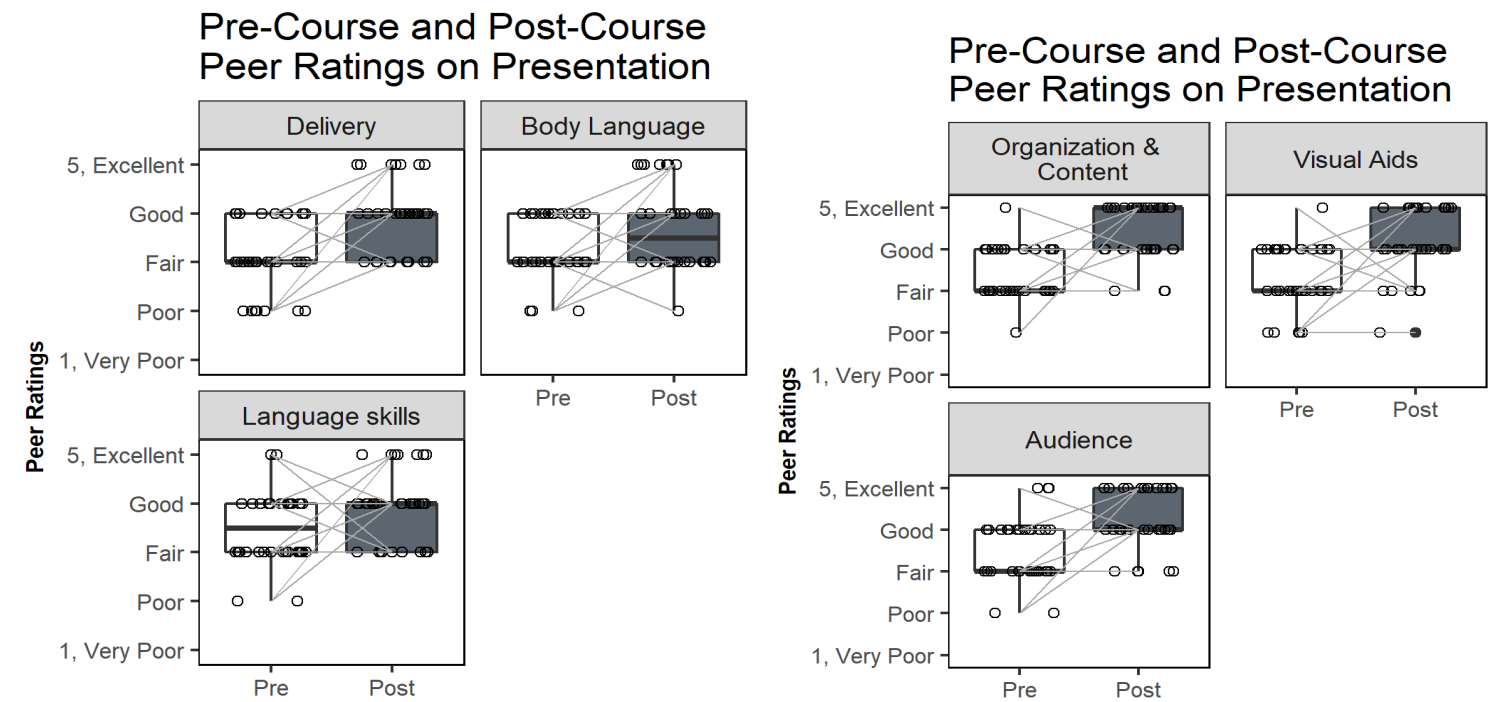

Figure 17. Group A Students' Professional Skills Development, N=34

\section{III.3.2. Results of the Peer-Evaluation for Activity 2 for Group A}

Group A participated in pre and post-VR simulation presentations. Each student was peerevaluated for each presentation based on the criteria stated in Figure 15. The results from both pre and post-peer-evaluations were analyzed using paired t-test to determine the mean difference between the two evaluations. For this paired t-test analysis, a confidence interval of $90 \%$ is set. Then, the obtained data were also graphically represented using box plots with line plots, which provides the correlation of the students' improvement throughout the VR-Training. Furthermore, results from the VR sessions allowed the authors to identify the students' main weaknesses, as well as provided relevant insight into their presentation delivery.

A Paired T-test analysis was conducted, as shown in Table 3. Based on these results, it can be concluded that the P-value for all the variables is less than 0.05 , indicating there is a significant difference in the means of the two data sets (i.e., pre-activity results and post- 
activity results). As shown in Table 3, the mean difference for each variable has a negative sign, indicating that the students did improve their different presentation skills through the VR Training.

Table 3. Paired T-Test Results for Group A - Activity 2

\begin{tabular}{|l|l|l|l|l|l|}
\hline & Mean & Std. Deviation & $\mathrm{t}$ & $\mathrm{df}$ & Sig. \\
\hline Delivery & -.10257 & .23777 & -2.440 & 34 & .017 \\
\hline Body Language & -.13714 & .27375 & -2.834 & 34 & .006 \\
\hline Language Skills & -.23761 & .20632 & -6.515 & 34 & .000 \\
\hline Organization \& Content & -.08939 & .12465 & -4.057 & 34 & .000 \\
\hline Visual Aids & -.15765 & .27165 & -3.283 & 34 & .002 \\
\hline Audience & -.75486 & .66031 & -6.567 & 34 & .000 \\
\hline
\end{tabular}

To compare and analyze the results of this training, boxplots were developed through RStudio, to graphically represent the respondents' development based on the VR Training provided. As shown in Figure 18, the students experienced growth across all the different criteria, including their ability to engage audiences, their body language, and delivery, among others. It is also worth noting that skills such as organization \& content and visual aids did not demonstrate such a significant improvement, as their median is maintained constant throughout the semester. Regardless, the difference in quartiles indicates that many students improved their skills in these areas. This indicated that the VR Presentation Simulation training successfully improved the students' presentation skills. Not all the communication skills improved significantly, which means that the undeveloped skills possibly require additional innovative training methods and/or continuous VR-presentation simulation training to observe a significant change in the students' performances. 

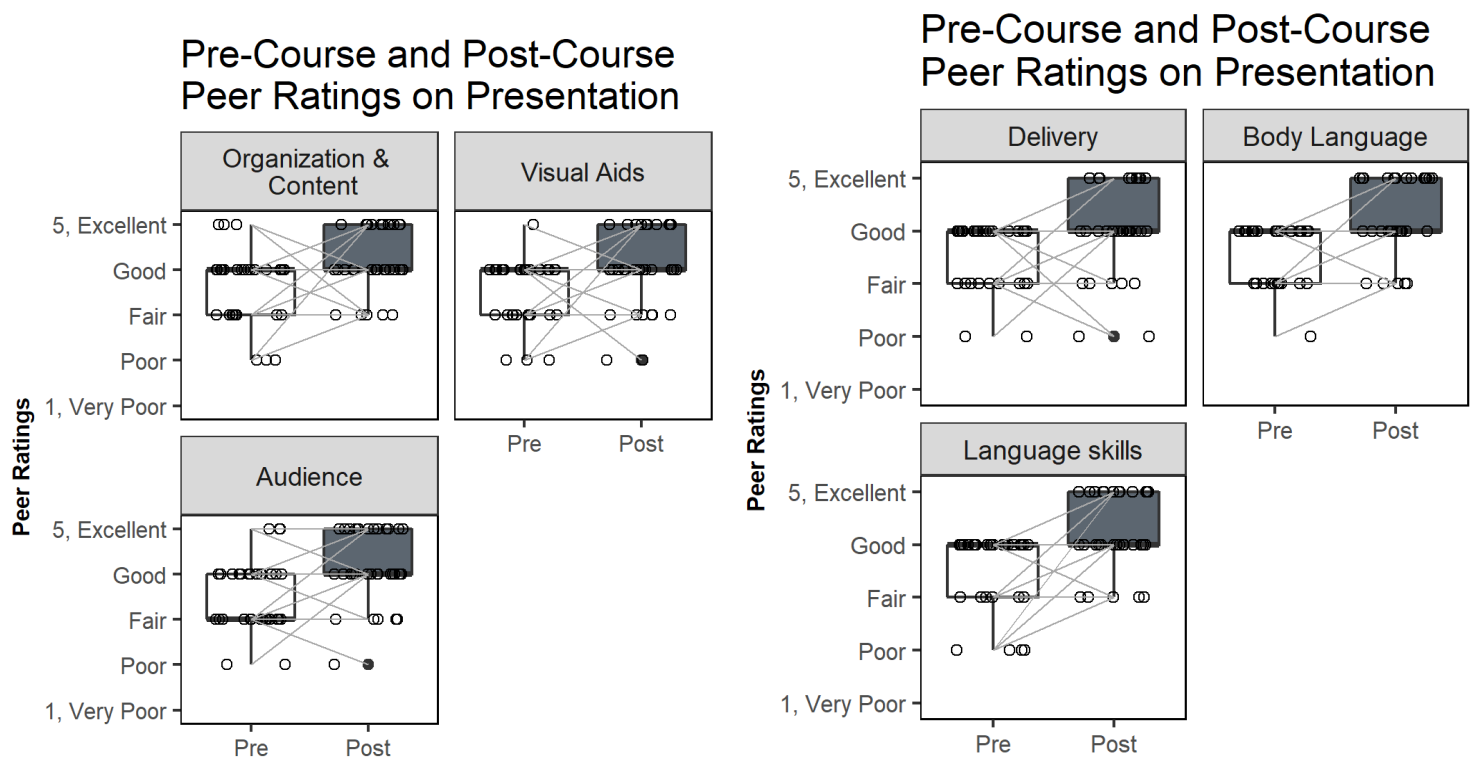

Figure 18.Group A Students' Professional Skill Development - Activity 2, N=34

Additionally, the obtained feedback from Virtual Orator (VO) was used to analyze specific presentation skills, such as eye contact, as shown in Figure 19. Based on the results, 91\% of the students demonstrated inappropriate eye contact, as they did not maintain sufficient and balanced contact with the audience. Improvement in eye contact during presentations can significantly increase a speaker's credibility in terms of qualification and effectiveness; thus, it is an important aspect to master when communicating with peers [47]. By offering students' specific statistics on their presentation mistakes, FIU CM students may then be advised to rehearse through the VR Simulations and reinforce their weaknesses to improve their communication skills. 


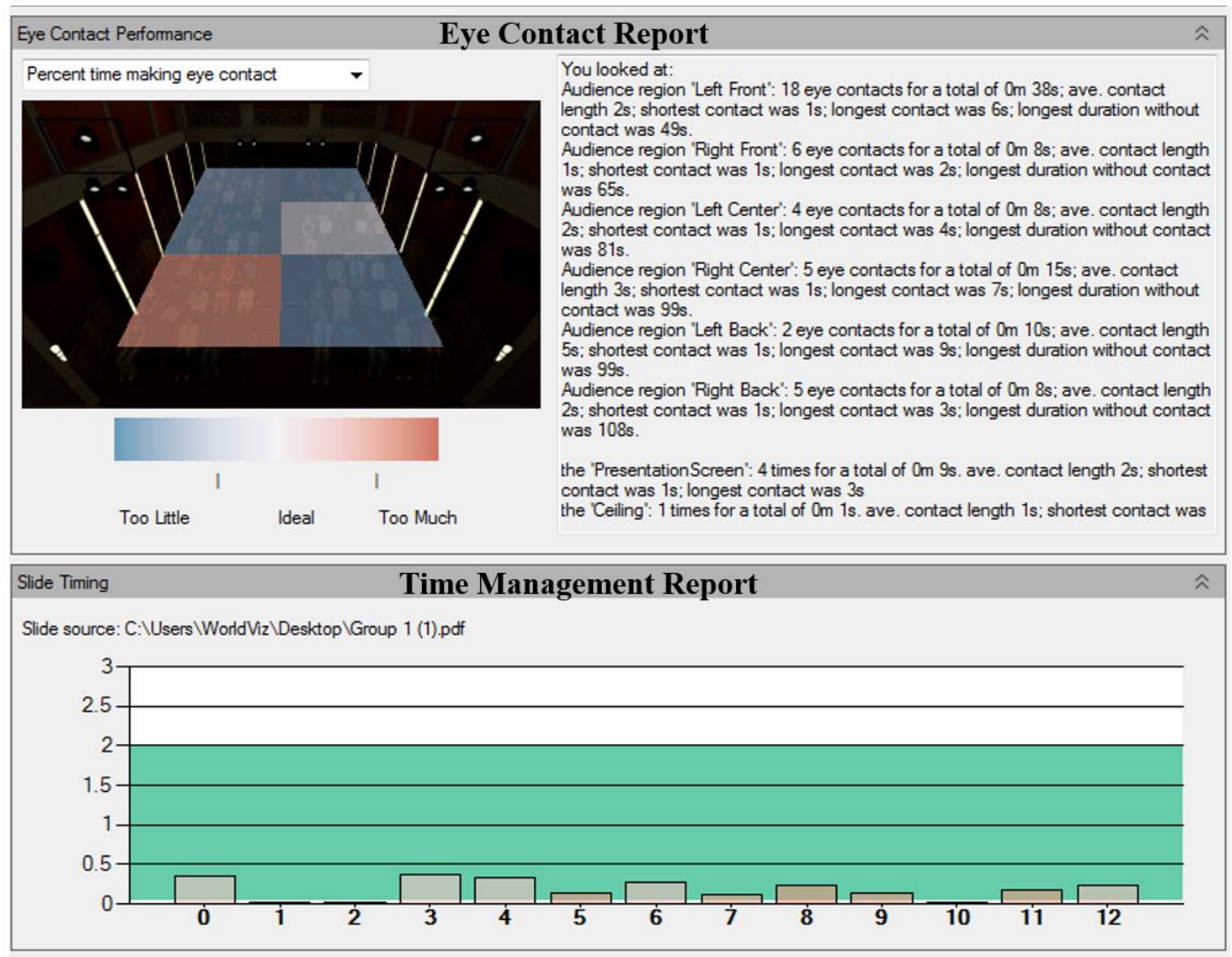

Figure 19. Virtual Orator Presentation Simulation Report

\section{III.4. Results for the Peer-Evaluations for Group B}

For Group B, peer-evaluations were conducted at the beginning and end of the semester, following students' participation in the three communication trainings. Students from BCN1013 did not evaluate their peers regarding their ability to engage audiences, as these students pertain to an online course, and there was no immediate in-person interaction with their peers. Table 4 and Table 5 shows the results of a paired T Tests developed based on the BCN1013 and BCN 2253 peer-evaluations. Based on these results, it can be concluded that the P-value for all the variables is less than 0.05 , indicating there is a significant difference in the means of the two data sets (i.e., pre-activities results, and post-activities 
results). As shown in Table 4 and Table 5, the mean difference for each variable has a negative sign, indicating that the students did improve their different presentation skills through their involvement in the three communication skills activities.

Table 4. Paired T-Test Results for BCN1013

\begin{tabular}{|c|c|c|c|c|c|}
\hline & Mean & Std. Deviation & $\mathrm{t}$ & $\mathrm{df}$ & Sig. \\
\hline Delivery & -0.08185 & 0.13697 & -2.672 & 19 & 0.015 \\
\hline Body Language & -0.10411 & 0.09599 & -4.850 & 19 & 0.000 \\
\hline Language Skills & -0.07508 & 0.10215 & -3.287 & 19 & 0.004 \\
\hline $\begin{array}{c}\text { Organization \& } \\
\text { Content }\end{array}$ & -0.03284 & 0.04575 & -3.210 & 19 & 0.005 \\
\hline Visual Aids & -0.10222 & 0.21138 & -2.163 & 19 & 0.044 \\
\hline
\end{tabular}

Table 5. Paired T Test Results for BCN2253

\begin{tabular}{|l|c|c|c|c|c|}
\hline & Mean & Std. Deviation & $\mathrm{t}$ & $\mathrm{df}$ & Sig. \\
\hline Delivery & -0.05606 & 0.02924 & $\begin{array}{c}- \\
13.422\end{array}$ & 48 & 0.000 \\
\hline Body Language & -0.00629 & 0.00618 & -7.121 & 48 & 0.000 \\
\hline Language Skills & -0.06736 & 0.10488 & -4.496 & 48 & 0.000 \\
\hline $\begin{array}{l}\text { Organization \& } \\
\text { Content }\end{array}$ & -0.07849 & 0.03917 & - & 48 & 0.000 \\
\hline Visual Aids & -0.02816 & 0.28649 & -0.688 & 48 & 0.495 \\
\hline Audience & -0.59268 & 0.19508 & - & 48 & 0.000 \\
\hline
\end{tabular}

To compare and analyze the results, boxplots were developed through RStudio, to graphically represent the respondents' development based on the training provided. As shown in Figure 20, the students experienced growth across all specified criteria, including their (1) delivery and (2) use of visual aids. It is also worth noting that skills such as 
organization \& content did not demonstrate such a significant improvement, as shown in Figure 20. Regardless, the differences in quartiles indicate that many students did improve their skills in these areas. Additionally, according to Figure 21, students from BCN2253 significantly improved their ability to engage audiences and their language skills. Nevertheless, results indicate that the vast majority improved their overall communication skills through their involvement in communication skills activities.
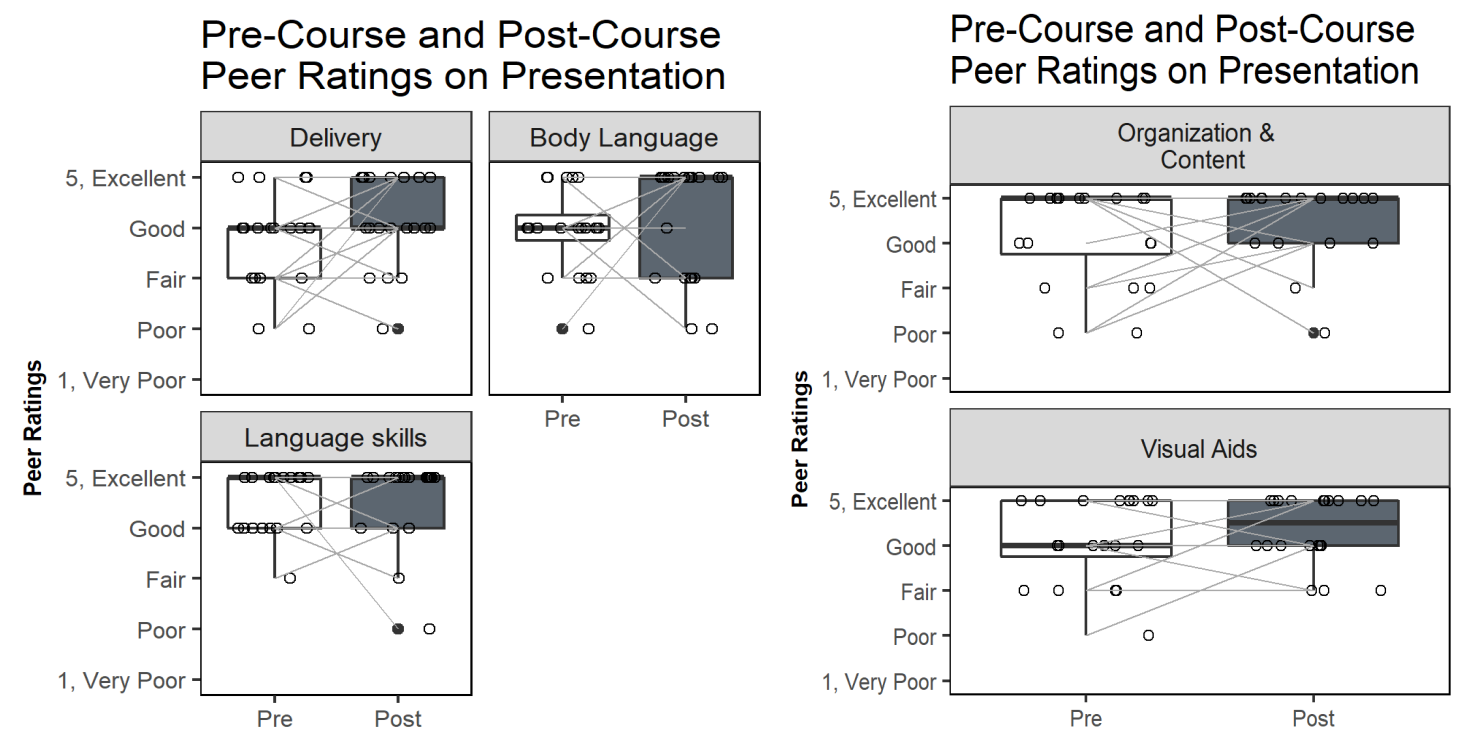

Figure 20. BCN1013 Student Skills Improvement Throughout the Activities 

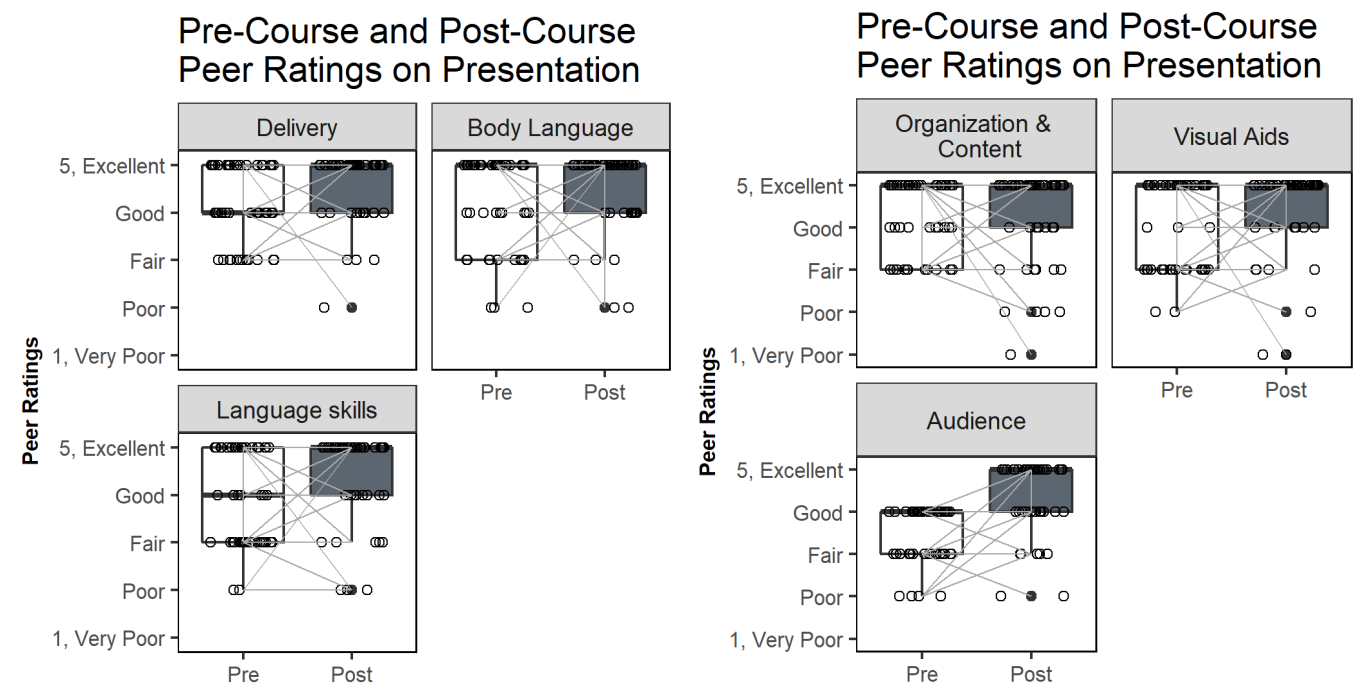

Figure 21. BCN2253 Student Skills Improvement Throughout the Activities

\section{III.5. Results of the Peer-Evaluations of Group C}

For Group C, peer-evaluations were conducted at the end of the semester, following students' participation in the three different communication trainings. Additionally, faculty evaluations were obtained for each students' presentation performance. Based on the students' peer-evaluations, as shown in Figure 22, participation in these activities has potentially influenced the students' presentation skills, as their post-activities results indicate their average skills rate in the mid 4's.

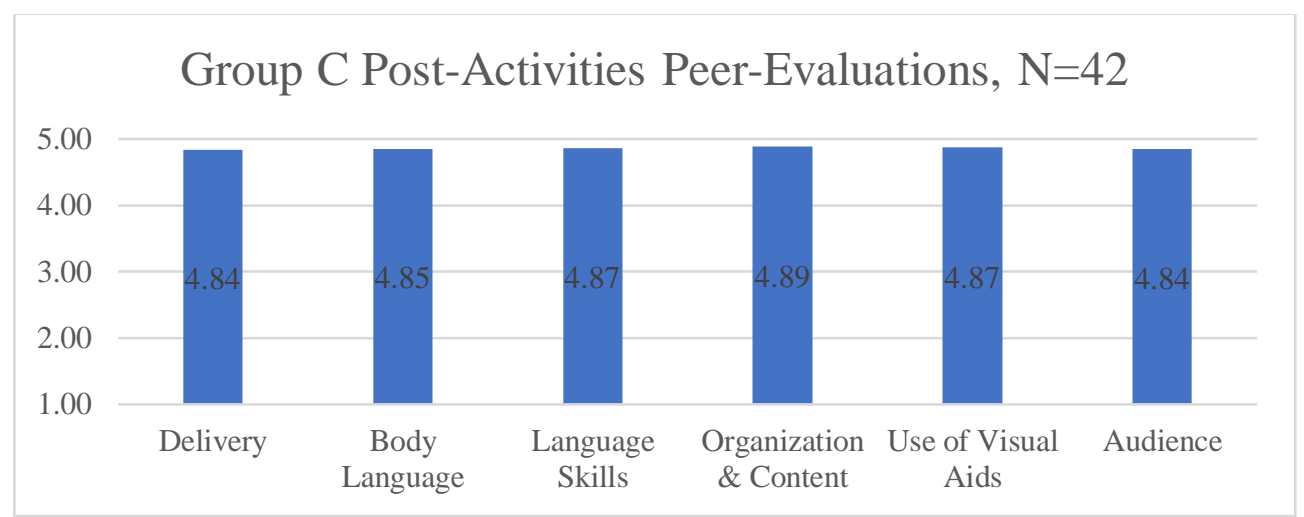

Figure 22. Group C Student Skills Improvement Throughout the Activities 
Additionally, based on the faculty evaluations shown in Figure 23, students' presentation skills potentially improved through the training, as their presentation delivery, body language, language skills, organization and content, use of visual aids, and audience obtained $4.69,4.67,4.85,4.85,4.54$, and 4.51 , respectively.

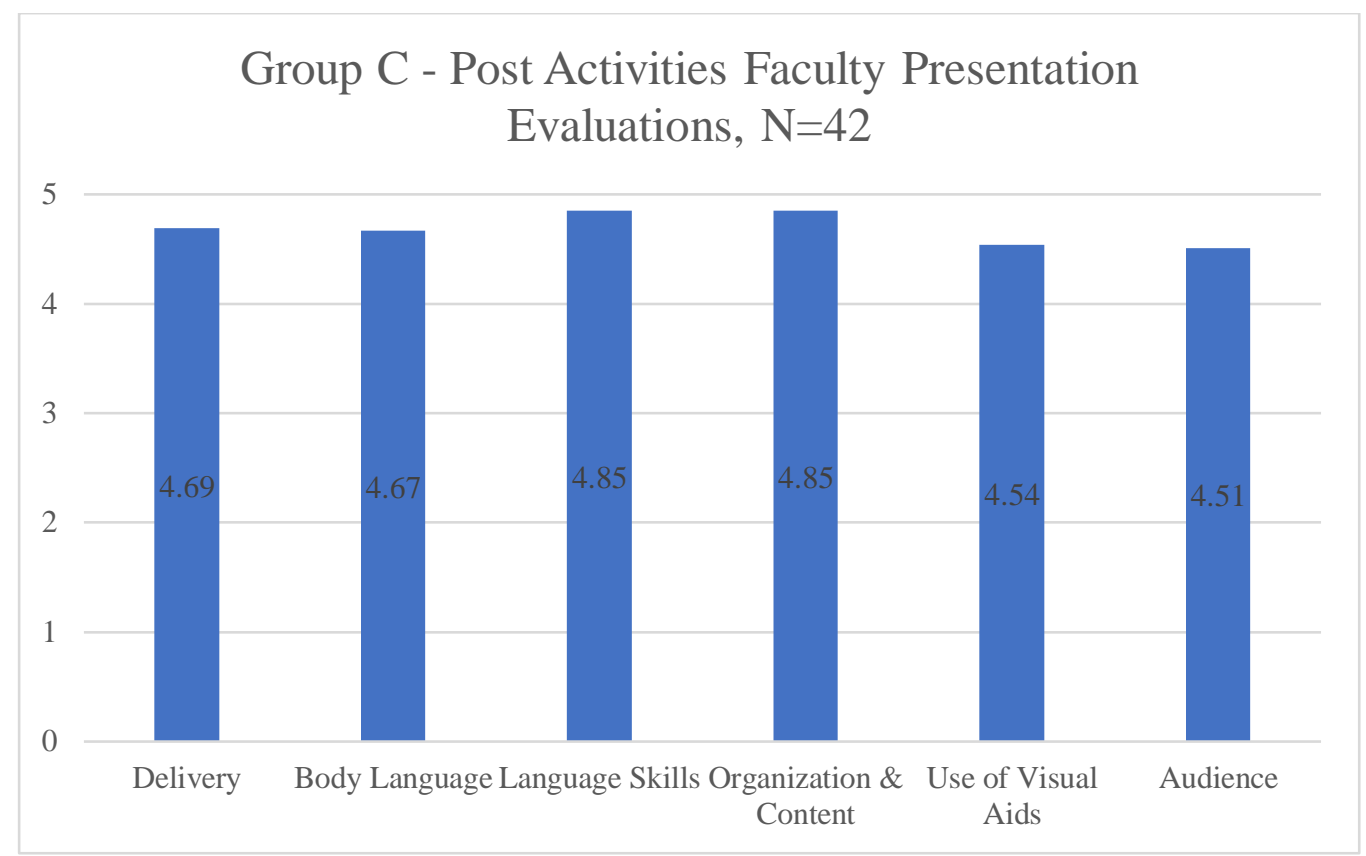

Figure 23. Group C Post-Activities Faculty Evaluations, $\mathrm{N}=42$

\section{III.7. Implementation of Activities - Conclusion}

To become competent construction managers, $\mathrm{CM}$ students must invest in developing their professional skills, such as communication and presentation skills. Participation in the three communication skill training allowed FIU CM students to improve all specified presentation skills, explicitly improving their body language and ability to engage audiences during presentations. Based on Group A results, Activity 1 was highly successful in improving students' organization \& content skills, use of visual aids, overall delivery, 
and ability to engage audiences, which supports the research hypothesis \#3. From this activity, language skills did not seem to improve significantly. Moreover, although these skills were also nurtured through Activity 2 based on the Group A results, additional skills as body language have extremely benefited due to Activity 2, supporting research hypothesis \#4. Additionally, based on the Group B results, the three activities successfully developed the students' skills, specifically their use of visual aids during presentations. Group C results, which correspond to those students who were peer- and faculty-evaluated at the end of the semester, showed significantly high ratings throughout their presentation skills evaluations, indicating that these three communication skills activities were, in fact, successful at promoting their professional growth. 


\section{CHAPTER IV}

\section{IV.1. Student Perception on Communication Skill Trainings - Exit Survey}

For the purpose of analyzing the targeted training' acceptance, an exit survey was distributed throughout the five CM courses involved in this research and gathered a total of 87 responses. The survey was distributed through Qualtrics, an online surveying tool. In this survey, students were able to rate their perception and effectiveness of the VR activity, as well as provide information regarding the skills, which students noticed improvement because of their engagement in their activities.

\section{IV.1.2. Exit Survey - Results}

Through this exit survey, students were asked to rank the three communication skills activities based on their effectiveness in improving their presentation skills. According to results, most of the students ranked the activities as shown in Figure 24, where 1 is considered the most effective and 3 the least effective activity.

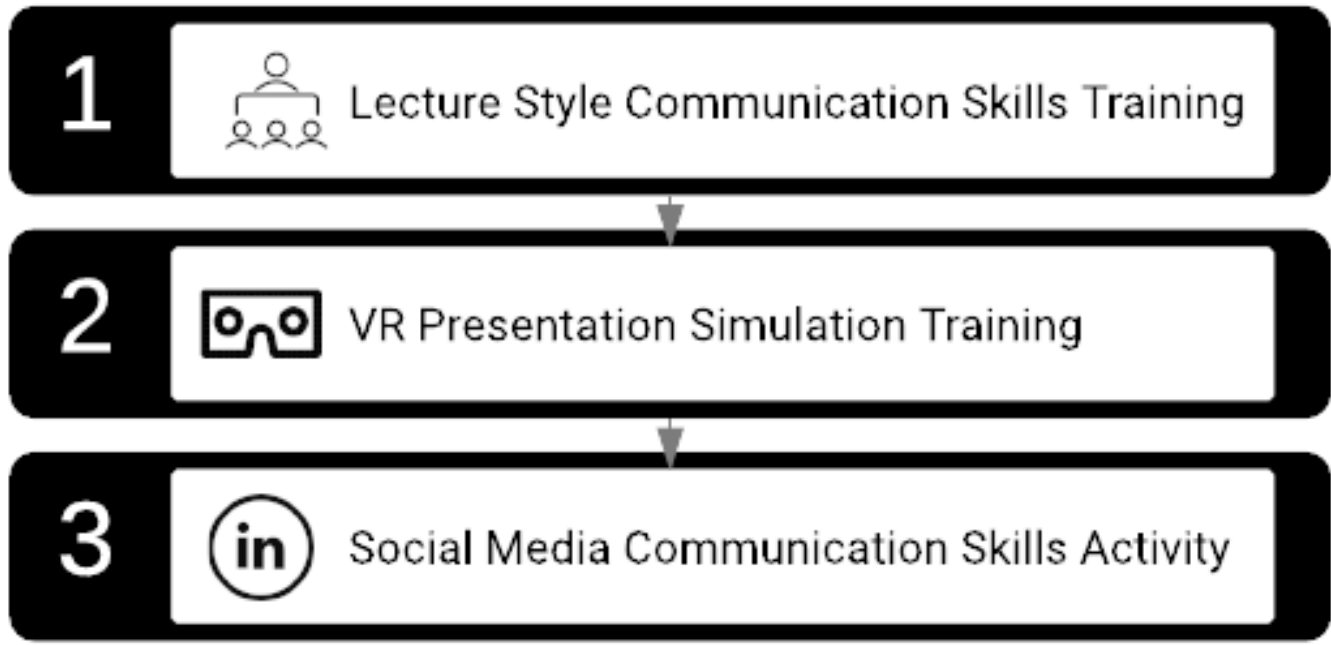

Figure 24. Student Ranking of the Activities, $N=87$ 
Additionally, students rated each of the activities depending on their level of effectiveness in improving their presentation skills. Based on the results shown in Table 6, the majority of students rated each activity as "Extremely Effective", with 51\% preferring Activity 1 , $45 \%$ for Activity 2 and $44 \%$ for Activity 3.

Table 6. Student Rating of Activities, $N=87$

\begin{tabular}{|l|l|l|l|}
\hline & Activity 1 & Activity 2 & Activity 3 \\
\hline $5-$ Extremely Effective & $51 \%$ & $45 \%$ & $44 \%$ \\
\hline 4- Highly Effective & $26 \%$ & $24 \%$ & $24 \%$ \\
\hline 3- Moderately Effective & $21 \%$ & $22 \%$ & $23 \%$ \\
\hline 2- Slightly Effective & $2 \%$ & $6 \%$ & $4 \%$ \\
\hline 1 - Ineffective & $0 \%$ & $2 \%$ & $5 \%$ \\
\hline
\end{tabular}

More specifically, students were surveyed on which specifics skills they believe the activities reinforced. Even though $52 \%$ of the students had previous communication trainings similar to Activity 1, they were able to increase their soft skills through all of the implemented activities. Based on Figure 25, the primary skills nurtured through Activity 1 was enthusiasm in presentation, eye contact, and time management. Regardless, only $0.74 \%$ believe they did not improve any skill throughout this activity. This indicates that Activity 1 was highly successful in improving students' presentation skills. 


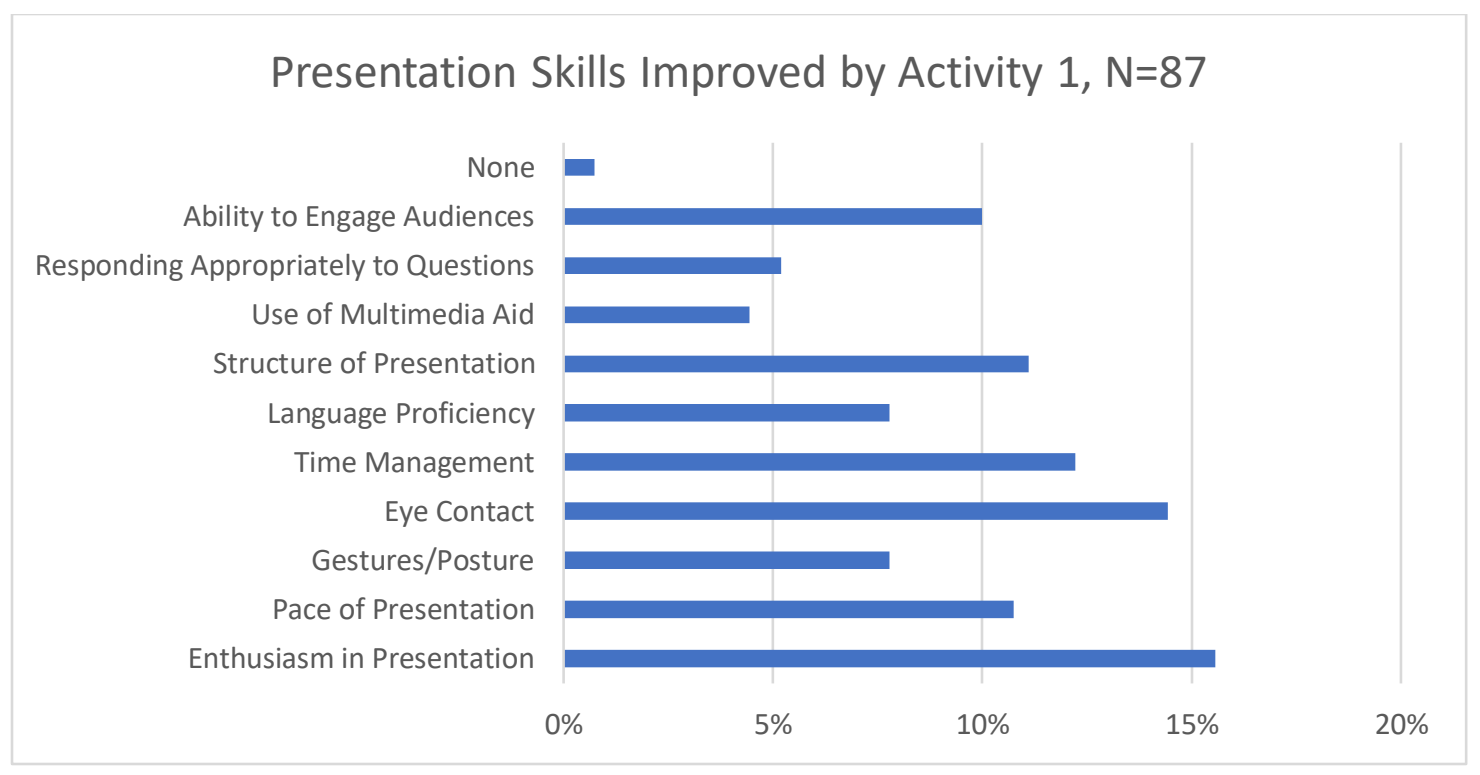

Figure 25. Presentation Skills Improved by Activities, $\mathrm{N}=87$

Based on the student perceptions Activity 2 helped improve students' lack of proper eye contact and time management deficiencies, as $47 \%$ and $41 \%$ of the respondents stated they improved such skills, respectively. Moreover, $81 \%$ of students have stated they would continue participating in this activity if it were available. Thus, the VR activity is an ideal alternative technique to improve the students' overall presentation skills, and results indicate its future implementation could further aid the students in their professional growth. 


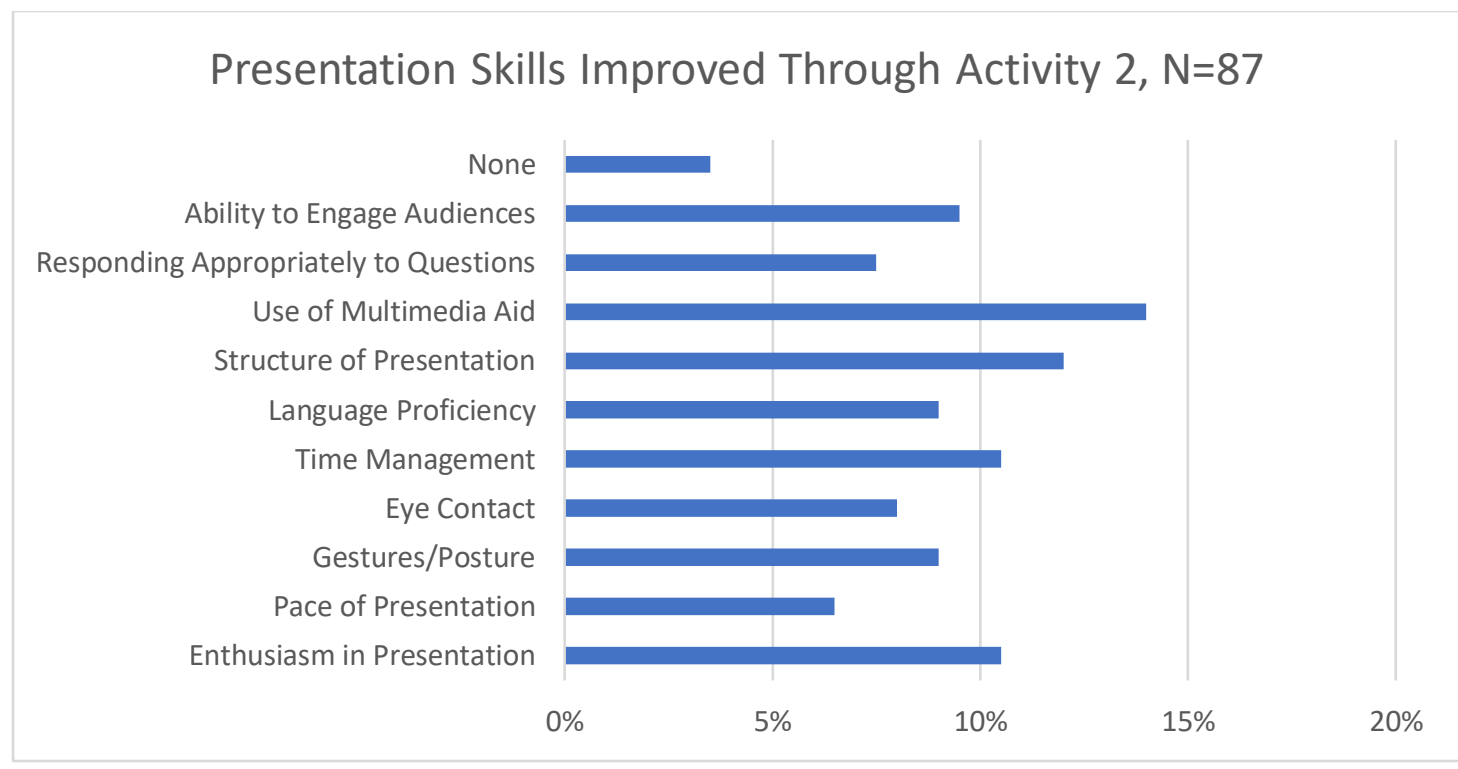

Figure 26. Presentation Skills Improved by Activity 2, N=87

Activity 3 allowed the students to engage with online communities. Even though $66 \%$ already had LinkedIn accounts, 34\% were new to this Social Media platform. Figure 27 shows the various skills that were reinforced due to the implementation of Activity 3.

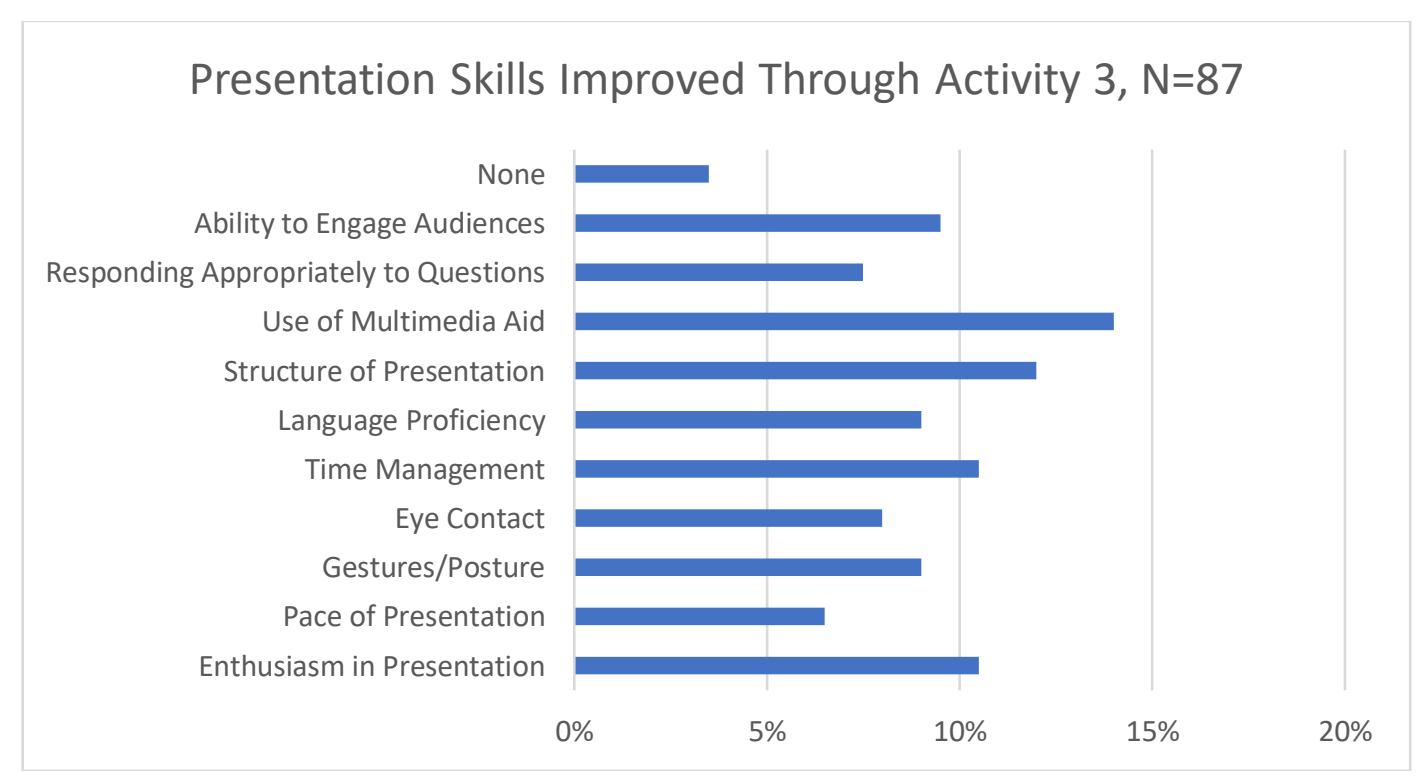

Figure 27. Student Improvement Through Activity 3, N=87 
Based on the students' perception, the skills that benefited the most from this activity were the use of multimedia, their enthusiasm during presentations, and the structure of the overall presentation. More specifically, $78 \%$ stated the opportunity to watch and share videos is the primary task that CM students benefited from. Meanwhile, $42 \%$ enjoyed reading articles, and 27\% from replying to their peers' posts, as shown in Figure 28.

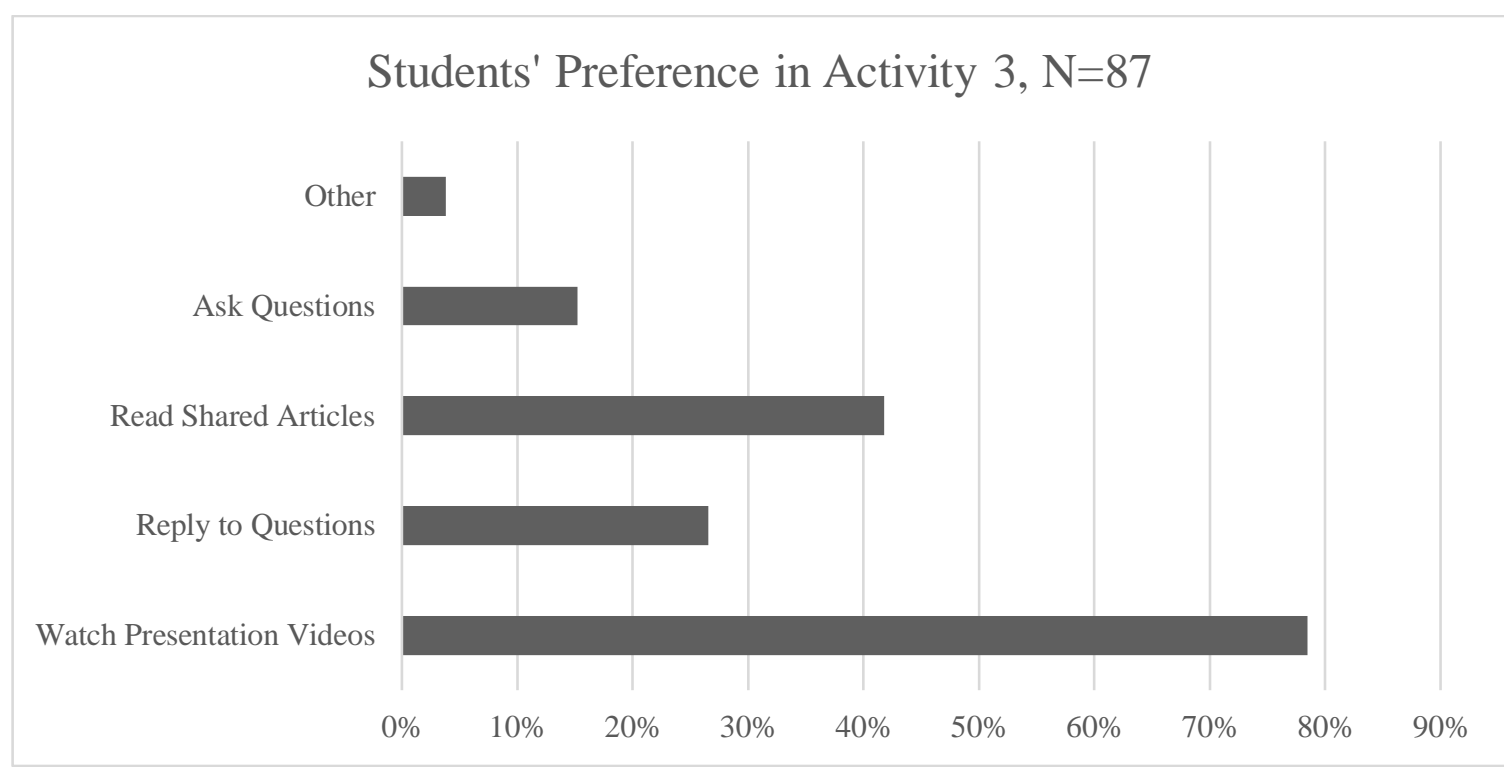

Figure 28. Students' Preference in Activity 3, N=87

Finally, CM students were asked to provide their feedback into the three implemented communication skills activities. Table 7, Table 8 and Table 9 show the students' feedback regarding the three Activities 1, 2, and 3, respectively.

Based on Table 7, CM students believe that Activity 1 was an active and informative experience, where they obtained important tips and general information regarding successful presentations. From learning emotion control techniques to presenting 
information in an organized, structured manner, students expressed their success in improving skills through this activity. While most of the responses are considered positive, some students did provide concerns about the activity, one of which is that students considered the activity to be interesting yet "too long". Additionally feedback from the activity, highlighted the students' difference in learning preferences, as some consider the activity effective since it is "better to hear this in person". In contrast, considered the activity not as effective and useful compared to practicing their presentations skills through in-class presentations.

Table 7. Sample of Student Feedback to Activity 1

\begin{tabular}{|c|}
\hline Student Feedback to the Lecture Style Presentation Skills Training \\
\hline learned how not to be scared when talking to an audience \\
\hline good \\
\hline $\begin{array}{l}\text { Highlights would be to keep eye contact when speaking to anyone, and to know the coward } \\
\text { you're going to be talking to. }\end{array}$ \\
\hline Knowledgeable \\
\hline Positive \\
\hline $\begin{array}{l}\text { In the in-class expert communication skills training, I learned strategies such as the type of } \\
\text { presentations to give depending on your audience. Even when presenting the presenter needs to } \\
\text { be knowledgeable enough to present without reading word for word. Communication strategy } \\
\text { which was a takeaway and feedback for me was eye contact. That was something new to me as } \\
\text { I am not used to presenting in front of experts or those in my same level of content knowledge. }\end{array}$ \\
\hline Practice \\
\hline Great student engaging \\
\hline Able to control nerves with the help of classmates \\
\hline $\begin{array}{l}\text { The expert helped me a lot in how to structure presentations. Also to identify my weakness and } \\
\text { use them in my favor when it comes to a presentation }\end{array}$ \\
\hline $\begin{array}{l}\text { Actually presenting and seeing others present was the most effective part. Would've liked } \\
\text { more engagement like that in the course }\end{array}$ \\
\hline training session was too long. \\
\hline
\end{tabular}

Regarding Activity 2, CM students provided positive feedback, as they considered the training "Impressive", "helped boost confidence and maintain eye contact with the audience" and "really helped in terms of pace, nervousness, to be bold, body gesture, ability 
to pass information to the audience, eye contact, to be time conscious and finally to be able to deliver your important pitch precisely and concisely." $22 \%$ of the CM students did not provide positive feedback to the training, as they stressed that the software should provide better graphics, or was not realistic enough. Additionally, some students believed it is an interesting concept, yet the equipment caused headaches or dizziness. Thus, this activity is effective in improving communication skills, yet improvements within the equipment could be made to ensure a better experience.

Table 8. Sample of Student Feedback to Activity 2

Student Feedback to the VR Presentation Simulation Training made me feel comfortable when I present in front of many people. it is great experience to practice on ant presentation.

It's a cool feature but to me the VR gives me a headache afterwards, but its great if you want to show off presentations -VR style

good experience

Very cool experience!

To present just based on the presentation you can see and not anything from the notes

The ability to gauge my knowledge of what was on the slides without being able to look at them, and also to control the pace and flow of my presentation.

The VR based presentation skills training mostly helps with persuasive presentations and was a great tool for online presentation skills.

It really helped in terms of pace, nervousness, to be bold, making body gesture, ability to pass your information to the audience, eye contact, to be time conscious and finally to be able to delivery your important pitch precisely and concisely.

It looked almost real, helps to build up the confidence.

It helps you with the eye contact

Interesting, a good application tool in order to practice time, pace, posture

Improve also my time management and my eye contact

no highlight people's faces quite blurry

I would prefer to have privacy to use the equipment. There were other people in the room, and it was hard to focus

Table 9 shows the students' feedback from Activity 3, where $95 \%$ of the students provided positive feedback to this Social Media activity. Students believe the activity was an 
"useful" and "informative" experience that allowed students to see how their peers approach their presentation struggles while learning about different approaches to presentation speeches, different techniques to improve eye contact and reduce nervousness, observing the different points of views to presentation practices and overall participating in an enriching online learning community. Regardless, $3 \%$ of the students did not provide any highlight to this activity, and $2 \%$ provided negative feedback, as they believed this activity was time-consuming and did not believe social media should be incorporated into the courses.

\section{Table 9. Sample of Student Feedback to Activity 3}

\begin{tabular}{|l|}
\hline \multicolumn{1}{|c|}{ Student Feedback to the Social Media Communication Skills Activity } \\
\hline $\begin{array}{l}\text { The LinkedIn social media activity was interesting because that was my first time linking a } \\
\text { video to a website to demonstrate an example to my explanation of presentation skills. }\end{array}$ \\
\hline the videos helped me with the presentation structured and the stage is handled \\
\hline The videos that people shared were very informative. \\
\hline I liked some of the posts other students posted, they gave me some great tips \\
\hline i watched many videos that helped me a lot on my presentation \\
\hline The posts help me to get tips on how to improve my communication skills. \\
\hline $\begin{array}{l}\text { It was interesting to see others peoples approaches or difficulties to accomplish the same task.( } \\
\text { public speaking) it helps you identify what your faults may have been }\end{array}$ \\
\hline $\begin{array}{l}\text { I learned a lot from a lot of videos and chats that my classroom colleagues and this made an } \\
\text { impact in my presentation skills and also thought me thing I never imagined or know about. So } \\
\text { the experience was very helpful and mind blowing. }\end{array}$ \\
\hline The LinkedIn activity gave me a chance to update my resume. \\
\hline $\begin{array}{l}\text { When reading other students post, you can see that everyone suffers from the same problem } \\
\text { which is EYE contact. Most of the students post something about body language. This helped } \\
\text { me use it in my last presentation. }\end{array}$ \\
\hline It was a great tool to exchange tips on presentation confidence. \\
\hline I read one post about looking to people's forehead instead of directly into their eyes \\
\hline This is terrible, too much stuff on my plate to be doing social media for homework \\
\hline I think it is time consuming.
\end{tabular}




\section{IV.1.3. Exit Survey - Conclusion}

Overall, based on the exit survey results, $99 \%$ of the students believe communication skills training activities would help CM students' professional development, and believe these implemented communication skills activities nurtured their presentation and communication skills. Further implementation of these activities within the CM courses at FIU, will potentially allow CM majors to further develop soft skills and increase their chances of thriving in their future careers. Moreover, the extensive positive feedback into the activities demonstrates these to be effective and accepted alternative learning methods for students to proactively obtain information from communication skills experts, immerse in interactive learning simulations, and participate in online communities that offer the opportunity to distribute information, take into account others' points of view and learn from their peers. 


\section{CHAPTER V}

\section{V.1. Limitations}

This research assessed the effects of the three communication/presentation activities on the performances of CM students' presentations. However, there were some limitations when conducting the research including: (1) the peer-evaluations conducted within this research may be subjective due to personal opinions and self-judgments; (2) the students' peerassessment could be influenced by the students' previous communication skills knowledge, despite the fact that the author believes this knowledge was sufficient to evaluate their peers appropriately; (3) the students' skills improvement throughout the course could be influenced by external factors throughout the duration of the semester and not only due to the trainings activity implemented; (4) Courses for which only peer-evaluations were obtained at the beginning of end of the semester, did not provide detailed information into which specific activity was more effective at improving students' skills; and (5) students who have filled the exit survey might possibly not have participated in all three activities, as certain were extra-credit and not obligatory for all students..

\section{V.2. Summary of the Research Study}

To advance construction management students' professional skills, this research first conducted a benchmark survey targeting 327 STEM undergraduate and graduate students at the Department of Engineering and Computing. The data obtained allowed the author to understand the deficiencies in FIU STEM students' communication skills, including CM majors. Then, to help these students at Florida International University further develop their communication and presentation skill sets, three different communication skills 
training activities were integrated into five upper and lower-level construction management courses, including undergraduate and graduate divisions. The five courses implementing this pilot study are BCN 5585 Sustainable Construction, BCN 4570 Sustainable Approach to Construction, BCN 1013 Principles of Construction Management, BCN 2253 Building Construction Drawing, and BCN 3727 Construction Sitework and Equipment. Students in the five courses were required to take part in multiple classroom-based communication skill training activities such as (1) Lecture Style Communication Skills Training; (2) VR Presentation Simulation Training and; (3) Social Media Communication Skills Activity. These three activities offered the CM students an opportunity to enhance their presentation performance, improve their confidence and overcome common presentation issues.

To analyze the effect of the trainings, the research deployed different evaluation methods, based on the various data gathered from each of the five courses. Courses BCN5585 and BCN4570 (referred to as Group A in this study) deployed peer-evaluations in between each activity implemented. Meanwhile, BCN1013 and BCN2253 (referred to as Group B in this study) deployed two peer-evaluations during the semester, before and after the students' involvement in the three activities. Lastly, BCN3727 (referred to as Group C in this study) conducted peer-evaluations and faculty-evaluations at the end of the semester, posterior to the students' participation in the three activities. Through these evaluations, the students' rated their peer's presentation based on specific criteria, allowing to measure the activities' impact on the construction management student's professional communication and presentation skill growth. 
Additionally, student exit surveys were conducted at the end of the semester to assess the students' experience and perception of each activity. Overall, the three implemented activities allowed the students to improve different communication skills, such as the ability to engage audiences, improve their body language, and deliver presentations in a more effective manner.

\section{V.3. Author's Interpretation of the Research}

The author found that the three communication skills trainings are extremely effective in improving the CM students' communication and presentation skills. As some training nurtured specific skills more than others, implementing the three different educational trainings allowed to develop many different communication and presentation skills. This variety in training methods also allowed to accommodate all students' learning preferences, as some prefer to learn by lectures, others by independent research and discussion forums, and others through more interactive approaches.

As evidence suggests, the three activities, Lecture-Style Communication Skills Training, VR Simulation Presentation Training, and the Social Media Communication Skills Activity were found to advance CM students' presentation skills. Group A results indicate that the Lecture-Style Communication Skills Training was particularly influential, and helped students improve their skills significantly. Thus, incorporating this type of activity throughout the CM courses as part of the syllabus, promises an effective approach to help nurture the students' presentation skills. The author suggests continuing to implement this 
activity through $\mathrm{CM}$ courses, when possible, to continue offering students the tools and knowledge needed to further improve their skills.

The author also believes incorporating more opportunities to rehearse these skills is a valuable option to explore in future semesters. As this offers the students the opportunity to implement the tools provided through the trainings. For courses that have course projects within the coursework, this could be achieved through constant project progress presentations. Students that participated in consequent peer-evaluations were observed to be more aware of their progress and more involved in the overall activities. This could also indicate that increasing the opportunity to present and evaluate their peers' presentations throughout the semester could influence their ongoing development. Also, constant peerevaluations allowed to measure each activity's impact thoroughly, thus allowing a more in-depth review of the activities and the skills each activity reinforced. Additionally, while peer-evaluations were an appropriate data collection method in this study, incorporating other data collection methods are encouraged since all courses might not be able to incorporate constant peer-evaluations into their syllabi and schedules.

Additionally, the VR Simulation Presentation Training could be even be more effective if implemented and offered throughout the entire semester. As this research study was initially analyzing the activity's effectiveness and acceptance, it was only implemented throughout one semester. These activities, if incorporated into the courses consecutively and become more available to the students, could increase their impact. Incorporating these activities into students' syllabi will also ensure their participation and development. 
Moreover, the author believes the VR activity could be even more effective if new methods of implementation are explored. The current implementation of the activity required the author to be in the lab managing the equipment. Even though this approach was successful, future implementation could conduct the activity in a more independent manner, thus ensuring the users are completely comfortable when using the VR. Also, in future work, when the software becomes available for different headsets, researchers could invest in other individual and inexpensive headsets such as the Google Cardboard VR, which in turn may offer the students' the opportunity to practice at their homes instead of on-campus spaces. This will stimulate their involvement, as the activity's availability will align with that of the students. Thus, considering that it is now proven that the activity is indeed successful, students will be able to continually rehearse their presentation through private VR simulations, rather than booking a slot to attend the activity on campus.

Currently, the Virtual Orator (VO) software is only available for the Oculus Rift Headset. The BEIL Lab, while it has even more advanced headsets, only possesses one headset compatible with the software, which is the Oculus Rift - Developer Kit. This developer version is an earlier version of the Oculus Rift, which unfortunately does not provide the same level of video and audio quality as other headsets. While the author believes this did not significantly impact the students' engagement in the activity, providing newer equipment in the future could potentially improve the overall experience.

Thus, the author recommends continuing the implementation of the Lecture-Style Communication Skills Training within the courses' syllabi, as well as offering the VR- 
based Presentation Simulation as an extra-curricular option for those students who prefer a more hands-on approach. The author believes that if possible, offering the students more opportunities to practice these skills in-class, would provide additional support into their development and offer the students a chance to showcase their skills and re-evaluate what skills they might need to continue to focus on. As the exit survey results indicate that the Social-Media Activity is believed to be the least effective, this activity could be also kept as extra-curricular to allow for a more focused implementation of Activity 1 and 2.

\section{V.4. Contribution to Knowledge}

The results of this research explore the current status of FIU CM students' professional skills, specifically communication and presentation skills. Through an extensive survey conducted throughout the College of Engineering and Computing, the students' main strengths and weaknesses regarding presentation skills were identified. Trends relating the students' socio-demographic profile to their current skills were recognized and analyzed. Moreover, this research has proven to advance Florida International University CM students' formal communication skills by creating different engaging educational environments, thus honing students' professional development. Through a Lecture-Style Communication Skills Training, a Virtual Reality (VR) Presentation Simulation Training, and a Social Media Communication Skills Activity, FIU construction management students were able to nurture and reinforce their presentation skills, including body language, ability to engage audiences and overall delivery. Students within five construction management courses were monitored throughout an entire semester, and their skills development were measured to assess the effectiveness of the aforementioned 
activities. Results indicate the activities were highly effective in nurturing the student's growth, as the vast majority of the students involved observed significant improvement throughout the study. Overall, the results of this thesis emphasize the significance to focus on developing our minority CM students' presentation skills in addition to providing valuable feedback and insights to the implementation of alternative learning pedagogies as in-class or informal trainings that integrate students' development skills in addition to technical contents.

\section{V.5. Future Studies}

Future studies will continue monitoring the activities' impact on CM students' professional growth, to further validate the results of the research and continue progressing the students' abilities. Additionally, future studies could seek to understand how STEM students' current skills and self-evaluation impacts the effectiveness of these communication skill trainings. Additional future studies could also seek to implement said activities in other STEM programs across FIU. Additionally, based on the feedback obtained in the exit survey, future studies could incorporate additional innovative learning techniques and enhance the implemented communication skills activities to improve the students' skills further. Also, future studies could analyze the effect of implementing a communication skills-oriented course within the CM graduate and undergraduate programs. 


\section{References}

[1] M. Kayyali, P. Pradhananga, and M. Elzomor, "Why Don't Undergraduate Engineering and Computing Students Pursue Combined BS/MS Degrees?," in ASEE Annual Conference \& Exposition (In-Press), 2020.

[2] S. Brunhaver, R. Korte, S. Barley, and S. Sheppard, "Bridging the Gaps Between Engineering Education and Practice," 2017.

[3] S. Cerri, "EFFECTIVE COMMUNICATION SKILLS FOR ENGINEERS," pp. 625-629, 2000.

[4] P. Pradhananga, G. Santi, and M. Elzomor, "Integrative Learning Approach to Improve Construction Students' Professional Skills and Engagement," in ASEE Annual Conference \& Exposition (In-Press), 2020.

[5] C. Hoover and J. Jones, "Improving Engineering Design: Design for Competitive Advantage," 1991.

[6] P. Pradhananga, G. Santi, and M. Elzomor, "Preparing the Future Workforce of Architecture, Engineering, and Construction for Robotic Automation Processes," ASC Proc., 2020.

[7] M. Riemer, "English and Communication Skills for the Global Engineer," Glob. J. Eng. Educ., vol. 6, no. 1, pp. 91-100, 2002.

[8] P. SAGEEV and C. ROMANOWSKI, "A Message from Recent Engineering Graduates in the Workplace: Results of a Survey on Technical Communication Skills," no. October, 2001.

[9] S. Kim, "Academic oral communication needs of East Asian international graduate students in non-science and non-engineering fields," English Specif. Purp., vol. 25, no. 4, pp. 479-489, 2006, doi: 10.1016/j.esp.2005.10.001.

[10] R. J. Eggert, "Engineering Design Education: Surveys of Demand and Supply," ASEE Аnпu. Conf. Expo. June 2003 Stay. Tune with Eng. Educ., pp. 1901-1912, 2002.

[11] Society of Manufacturing Engineers Education Foundation, "Manufacturing Education Plan: Phase 1 Report-Industry Identifies Competency Gaps Among Newly Hired Engineering," 1997.

[12] A. Keane and I. S. Gibson, "Communication Trends in Engineering Firms: Implications for Undergraduate Engineering Courses," Int. J. Eng. Educ., vol. 15, no. 2, pp. 115-121, 1999.

[13] P. Koen and P. Kohli, "ABET 2000: what are the most important criteria to the supervisors of new engineering undergraduates?," ASEE Annu. Conf. Proc., 1998.

[14] J. Lang and F. McVey, "Industry Expectations of New Engineers - A Survey to Assist Curriculum Designers James D . Lang and Francis D . McVey," ASEE.

[15] J. Van Emden and L. Becker, Presentation Skills For Students, 3rd ed. 2016. 
[16] A. Bradbury, Successful Presentation Skills, 3rd ed. 2006.

[17] L. A. Riley, P. Furth, and J. Zelmer, "Assessing Our Engineering Alumni: Determinants of Success in the Workplace," 2000 ASEE/Gulf-Southwest Sect. Annu. Conf., 2000.

[18] A. L. Darling and D. P. Dannels, "Practicing engineers talk about the importance of talk: A report on the role of oral communication in the workplace," Commun. Educ., vol. 52, no. 1, pp. 1-16, 2003, doi: 10.1080/03634520302457.

[19] H. Wu, C. Sun, and T. Li, "Study on the Structure of a Risk Management Framework Based on BIM," ICCREM 2014 Smart Constr. Manag. Context New Technol. - Proc. 2014 Int. Conf. Constr. Real Estate Manag., pp. 312-319, 2014, doi: 10.1061/9780784413777.038.

[20] F. T. Edum-Fotwe and R. McCaffer, "Developing project management competency: Perspectives from the construction industry," Int. J. Proj. Manag., vol. 18, no. 2, pp. 111-124, 2000, doi: 10.1016/S0263-7863(98)90075-8.

[21] K. Alshare and N. Hindi, "The importance of presentation skills in the classroom: students and instructors perspectives," J. Comput. Sci. Coll., vol. 19, no. 4, pp. 615, 2004.

[22] C. Savander-Ranne, O. P. Lundén, and S. Kolari, "An alternative teaching method for electrical engineering courses," IEEE Trans. Educ., vol. 51, no. 4, pp. 423-431, 2008, doi: 10.1109/TE.2007.912500.

[23] T. J. Kennedy and M. R. L. Odell, "Engaging Students In STEM Education," Sci. Educ. Int., vol. 25, no. 3, pp. 246-258, 2014.

[24] J. V. Farr and B. A. Bowman, "Abet accreditation of engineering management programs: Contemporary and future issues," EMJ - Eng. Manag. J., vol. 11, no. 4, pp. 7-13, 1999, doi: 10.1080/10429247.1999.11415044.

[25] G. Tryggvason and D. Apelian, "Re-Engineering Engineering Education for the Challenges of the 21st Century," JOM, no. 1, p. 1610, 2006.

[26] M. Elzomor and O. Youssef, "Coupling Haptic Learning with Technology To Advance Informal STEM Pedagogies," Am. Soc. Eng. Educ.

[27] P. Pradhananga, M. Elzomor, D. Ph, A. M. Sadri, and D. Ph, "Integrating Social Media Platforms in Construction Education to Increase Student Engagement," in ASC Proceedings, 2020.

[28] A. Lenhart and K. Purcel, "Social Media and mobile Internet Use Among Teens and Young Adults (Vol. 01)," 2010. [Online]. Available: http://pewinternet.org/Reports/2010/Social Media-and-Young-Adults.aspx\%0A.

[29] Y. Liu, "Social Media as a Learning Resource," J. Educ. Technol. Dev. Exch. (JETDE), 3(1), 2010.

[30] C. C. Cheston, T. Flickinger, and M. S. Chisolm, "Social Media Use in Medical Education: A Systematic Review," Acad. Med., 2013. 
[31] M. Moran, J. Seaman, and H. Tinti-Kane, "Teaching, Learning, and Sharing: How Today’s Higher Education Faculty Use Social Media,” no. April, 2011.

[32] C. Greenhow and C. Lewin, "Social media and education: reconceptualizing the boundaries of formal and informal learning," Learn. Media Technol., vol. 41, no. 1, pp. 6-30, 2016, doi: 10.1080/17439884.2015.1064954.

[33] K. Rutten and G. Vandermeersche, "Integrating Social Media in Education," Comp. Lit. Cult. (15)3., 2013.

[34] E. Ivala and D. Gachago, Social Media for Enhancing Student Engagement: The Use of Facebook and Blogs at a University of Technology. 2012.

[35] J. Psotka, "Immersive training systems: Virtual reality and education and training," Instr. Sci., vol. 23, no. 5-6, pp. 405-431, 1995, doi: 10.1007/BF00896880.

[36] L. Freina and M. Ott, "A literature review on immersive virtual reality in education: State of the art and perspectives," Proc. eLearning Softw. Educ. (eLSE)(Bucharest, Rom. April 23--24, 2015), p. 8, 2015, doi: 10.12753/2066026X-15-020.

[37] L. De Grez, M. Valcke, and I. Roozen, "The impact of an innovative instructional intervention on the acquisition of oral presentation skills in higher education," Comput. Educ., vol. 53, no. 1, pp. 112-120, 2009, doi:

10.1016/j.compedu.2009.01.005.

[38] R. R. Hammer et al., "Telling the Patient's Story: Using theatre training to improve case presentation skills," Med. Humanit., vol. 37, no. 1, pp. 18-22, 2011, doi: 10.1136/jmh.2010.006429.

[39] C. M. Smith and T. M. Sodano, "Integrating lecture capture as a teaching strategy to improve student presentation skills through self-assessment," Act. Learn. High. Educ., vol. 12, no. 3, pp. 151-162, 2011, doi: 10.1177/1469787411415082.

[40] J. J. Evans, A. S. Van Epps, M. T. Smith, S. A. Matei, and E. Garcia, “A transdisciplinary approach for developing effective communication skills in a first year STEM seminar," ASEE Annu. Conf. Expo. Conf. Proc., vol. 122nd ASEE, no. 122nd ASEE Annual Conference and Exposition: Making Value for Society, 2015, doi: 10.18260/p.23468.

[41] J. FORD and L. A. RILEY, "Integrating Communication and Engineering Education: A Look at Curricula, Courses, and Support Systems.," J. Eng. Educ., vol. 92, no. 4, pp. 325-328, 2003.

[42] M. C. Benton, E. Pappas, and M. C. Benton, "WordPress + Qualtrics : A Plugin Supporting Research and New Pedagogy to Develop Personal Sustainability via $360^{\circ}$ Evaluation WordPress + Qualtrics : A Plugin Supporting Personal Sustainability via $360^{\circ}$ Evaluation," 2011.

[43] J. Y. Campbell, J. J. Campbell, J. W. Campbell, A. Lo, and C. MacKinlay, The Econometrics of Financial Markets. 1997. 
[44] H. London, "Transformations: Cultural Challenges Faced by First-Generation Students," New Dir. Community Coll., vol. 80.

[45] D. Kumrow and B. Dahlen, "Is Peer Review an Effective Approach for Evaluating Teachers?," Clear. House A J. Educ. Strateg. Issues Ideas, vol. 75, no. 5, pp. 238241, 2002, doi: 10.1080/00098650209603947.

[46] C. Bauer, K. Figl, M. Derntl, P. P. Beran, and S. Kabicher, "The student view on online peer reviews," Proc. Conf. Integr. Technol. into Comput. Sci. Educ. ITiCSE, pp. 26-30, 2009, doi: 10.1145/1562877.1562892.

[47] S. Beebe, "Eye Contact: A Nonverbal Determinant of Speaker Credibility," Speech Teach., vol. 23, 2009. 


\section{Appendix}

Appendix A - Student Feedback into Activity 1

Student Feedback to the Lecture Style Presentation Skills Training

learned how not to be scared when talking to an audience

good

Highlights would be to keep eye contact when speaking to anyone, and to know the coward you're going to be talking to.

Knowledgeable

Positive

In the in-class expert communication skills training, I learned strategies such as the type of presentations to give depending on your audience. Even when presenting the presenter needs to be knowledgeable enough to present without reading word for word. Communication strategy which was a takeaway and feedback for me was eye contact. That was something new to me as I am not used to presenting in front of experts or those in my same level of content knowledge.

Practice

Great student engaging

Able to control nerves with the help of classmates

The expert helped me a lot in how to structure presentations. Also to identify my weakness and use them in my favor when it comes to a presentation

Presentations were insightful and informative.

learning to engage audiences

The presenter gave key points such as organizing your speech and practicing before the actual presentation

Continuously interesting

knowledgeable

Helped put public speaking in to perspective

Structure of presentation and enthusiasm

Structure

Our presenter brought many great points and skills to her presentation

they highlighted the important things on how we can do great presentation like know your audience and make eye contact.

The speaker provided valuable insights into how to prepare and conduct a public speaking presentation.

Understand your pitch

training session was too long.

Learning presentation skills

The professor helped with explaining that being nervous is normal

The commercials and how the presentation were delivered

Practice when doing the final presentation

Effective

Learning concepts

Effective

Better to hear things in person 
Eye opening on finer details

the appropriate way to communicate and deliver the message to the audience

Actually presenting and seeing others present was the most effective part. Would've liked more engagement like that in the course

great explanation of to improve the communication skills, but I prefer other ways of learning,

like practicing

Helped me improve my public speaking skills

Learned a lot.

I was able to work on my phobia of public presentation.

Very informative and impactful experience so far

The expert communication skill training helped me with the basics of the presentation to

complete with proficient language and time.

It gave me an opportunity to work through my anxiety of presenting in front of an audience.

because of the in-class room expert communication, $i$ was able to make my 3rd speech more

effective. But I still need to improve on certain things.

I like the impromptu speech the most. It was challenging but worthwhile.

Got to see a how a professional presenter and made me had the opportunity to learn from it and apply it during the course presentations. Always giving my $150 \%$ in each one.

A little shaky at first but sharing with peers on LinkedIn helped

engagement of class

In class communication enhanced the self confidence

I could see myself in my first presentation and the last one and I think that I did it much better.

I am very shy to talk in front of people.

Time management

Gaining self-confidence to deliver content effectively

It was a challenge

effective use of time management

Experience person talk was beneficial

Very good experience. It helps us to get used to have an audience

Great

Improve my time management

It helps a lot all the tips to not feel nervous in front a crowd

The experience helped me a lot manage time and boosting my confidence during presenting

It was good but a little bit too long

I like the time limit on the presentations. It forces you to be concise and to practice your

delivery several times beforehand. Even with this it is still challenging, and one can still miss

the three-minute mark!

Great way of improvement

Out of my comfort zone but it was nice

Coming up with quick ideas

Very useful, Practice makes perfect.

Interesting topics

The presentation Tips

Learned how to be a better presenter 
Great

Great Suggestions from Professor and Critical Reviews from Classmates

Awesome 


\section{Appendix B - Student Feedback into Activity 2}

\begin{tabular}{|c|}
\hline Student Feedback to the VR Presentation Simulation Training \\
\hline the VR-based Presentation Skills Training: \\
\hline using technology to raise my communication skills \\
\hline realistic \\
\hline no highlight people's faces quite blurry \\
\hline $\begin{array}{l}\text { made me feel comfortable when I present in front of many people. it is great experience to } \\
\text { practice on ant presentation. }\end{array}$ \\
\hline $\begin{array}{l}\text { It's a cool feature but to me the VR gives me a headache afterwards, but its great if you want to } \\
\text { show off presentations -VR style }\end{array}$ \\
\hline it allowed me to practice \\
\hline I did not have get the chance to try the VR, but from other students they highly recommend it. \\
\hline good experience \\
\hline Very cool experience! \\
\hline VR aspect \\
\hline To present just based on the presentation you can see and not anything from the notes \\
\hline The desire to engage the audience \\
\hline $\begin{array}{l}\text { The ability to gauge my knowledge of what was on the slides without being able to look at } \\
\text { them, and also to control the pace and flow of my presentation. }\end{array}$ \\
\hline $\begin{array}{l}\text { The VR based presentation skills training mostly helps with persuasive presentations and was a } \\
\text { great tool for online presentation skills. }\end{array}$ \\
\hline Teaches you eye contact \\
\hline Real life simulation \\
\hline Practice and let one management \\
\hline $\begin{array}{l}\text { My first experience was in the last semester when I used the VR training. using the VR tool } \\
\text { helped me to speak fluently and make an eye contact with the audience. }\end{array}$ \\
\hline Learning presentation skills \\
\hline Learning how to speak in front of an audience \\
\hline Language proficiency \\
\hline I'd consider it but if it were accessible off campus \\
\hline It was very interesting \\
\hline It was my 1 st time using virtual reality glasses at school. \\
\hline $\begin{array}{l}\text { It really helped in terms of pace, nervousness, to be bold, making body gesture, ability to pass } \\
\text { your information to the audience, eye contact, to be time conscious and finally to be able to } \\
\text { delivery your important pitch precisely and concisely. }\end{array}$ \\
\hline It looked almost real, helps to build up the confidence. \\
\hline It helps you with the eye contact \\
\hline It helped me to visualize how to speak to an audience and feel less nervous \\
\hline It helped me boost my confidence and to maintain eye contact with the audience. \\
\hline It betters Eye contact and body language \\
\hline Interesting, a good application tool in order to practice time, pace, posture \\
\hline Improve also my time management and my eye contact \\
\hline
\end{tabular}


Impressive

I would prefer to have privacy to use the equipment. There were other people in the room, and it was hard to focus

I was surprised to see different personalities of members in the audience.

I was able to practice giving a speech from a podium

I think that I did much better in my last presentation

I loved the technology, but not so great for responding to questions and such

Helped with eye contact and audience engagement

Having an audience gave me a chance to correct some of my mistakes.

Great tool to achieve confidence

Great learning with the eye contact

Great feedback is given, great way to practice.

Great experience

Good tool for simulation

Give the presenter the atmosphere and practice

Fun to do

Eye contact and engagement of audience

Excellent

Effective

Effective

Educating

Did help with my presentation skills

Cool and useful

Can practice my presentation and see what I need to improve.

Awesome

Amazing, amazing, amazing 


\section{Appendix C - Student Feedback into Activity 3}

\begin{tabular}{|l|}
\hline \multicolumn{1}{|c|}{ Student Feedback to the Social Media Communication Skills Activity } \\
\hline Got to meet new people \\
\hline getting to see other students' perspective on how speeches. \\
\hline new to me \\
\hline $\begin{array}{l}\text { The LinkedIn social media activity was interesting because that was my first time } \\
\text { linking a video to a website to demonstrate an example to my explanation of } \\
\text { presentation skills. }\end{array}$ \\
\hline Able to gather information from others \\
\hline the videos helped me with the presentation structured and the stage is handled \\
\hline The videos that people shared were very informative. \\
\hline Reading different articles to understand communication better \\
\hline I saw other videos/articles posted by peers that will help me in the future \\
\hline Useful tips \\
\hline get information \\
\hline Interacting with others \\
\hline Different approaches to performing a presentation \\
\hline Learning about different approaches to give speeches \\
\hline I liked some of the posts other students posted, they gave me some great tips \\
\hline i watched many videos that helped me a lot on my presentation \\
\hline It was very nice \\
\hline I can see how my peers approach their struggles \\
\hline Presentation skills \\
\hline It helped with tips for presenting \\
\hline It allowed me to explore opportunities within my profession \\
\hline There was some great advice posted by students \\
\hline Effective \\
\hline Great technique \\
\hline Effective \\
\hline None \\
\hline Good \\
\hline The posts help me to get tips on how to improve my communication skills. \\
\hline $\begin{array}{l}\text { It was interesting to see others peoples approaches or difficulties to accomplish the } \\
\text { same task.( public speaking) it helps you identify what your faults may have been }\end{array}$ \\
\hline There were great videos \\
\hline Gave me tips and tricks to overcome presentation anxiety \\
\hline Extra credit is beneficial \\
\hline $\begin{array}{l}\text { It gave me a chance to share my own personal interests in construction an } \\
\text { sustainability. }\end{array}$ \\
\hline $\begin{array}{l}\text { I learned a lot from a lot of videos and chats that my classroom colleagues and this } \\
\text { made an impact in my presentation skills and also thought me thing I never imagined } \\
\text { or know about. So the experience was very helpful and mind blowing. }\end{array}$ \\
\hline
\end{tabular}


I am active using LinkedIn and Twitter from the past 5 years. It helps a lot to build your profile

The LinkedIn activity gave me a chance to update my resume.

When reading other students post, you can see that everyone suffers from the same problem which is EYE contact. Most of the students post something about body language. This helped me use it in my last presentation.

I think it is time consuming.

Before I didn't know the importance LinkedIn had, but now I do and is a good way to know many people from same or different careers to share experience.

It was a great tool to exchange tips on presentation confidence.

Post on how to deal with fear of presenting

Good

I really liked the activity because besides getting articles of other classmates, we could also get in contact with them by this social media.

Interactive

I read one post about looking to people's forehead instead of directly into their eyes

Seeing how many TED talks that were on presenting

Discovering New technologic means and methods

New ideas from colleagues

There were very interesting posts that were shared by my colleagues

This is terrible, too much stuff on my plate to be doing social media for homework

See different points of view about how the people feel presenting

Helped me learn about techniques while presenting.

It helps understand others struggle and how the overcome them

The ability to collaborate with others and share in our continued growth together.

Linked with new people

Connects you to others well

Very useful information shared

Useful

Made more familiar with the website

It was cool to see everyone's posts

Informative!

Got to know so many things from what other students shared on the LinkedIn group

Awesome 